\title{
Review Article \\ Genetics of Type 2 Diabetes: Insights into the Pathogenesis and Its Clinical Application
}

\author{
Xue Sun, ${ }^{1}$ Weihui $\mathrm{Yu}^{2}$ and Cheng $\mathrm{Hu}^{1,3}$ \\ ${ }^{1}$ Shanghai Diabetes Institute, Shanghai Clinical Center for Diabetes, Shanghai Key Clinical Center for Metabolic Disease, Shanghai \\ Key Laboratory of Diabetes Mellitus, Shanghai Jiao Tong University Affiliated Sixth People's Hospital, Shanghai 200233, China \\ ${ }^{2}$ Department of Endocrinology and Metabolism, Wenzhou Medical University Affiliated First Hospital, Wenzhou 325000, China \\ ${ }^{3}$ Shanghai Jiao Tong University Affiliated Sixth People's Hospital, South Branch, Shanghai 200233, China
}

Correspondence should be addressed to Cheng Hu; alfredhc@sjtu.edu.cn

Received 7 March 2014; Accepted 22 March 2014; Published 17 April 2014

Academic Editor: Jiarui Wu

Copyright (C) 2014 Xue Sun et al. This is an open access article distributed under the Creative Commons Attribution License, which permits unrestricted use, distribution, and reproduction in any medium, provided the original work is properly cited.

With rapidly increasing prevalence, diabetes has become one of the major causes of mortality worldwide. According to the latest studies, genetic information makes substantial contributions towards the prediction of diabetes risk and individualized antidiabetic treatment. To date, approximately 70 susceptibility genes have been identified as being associated with type 2 diabetes (T2D) at a genome-wide significant level $\left(P<5 \times 10^{-8}\right)$. However, all the genetic loci identified so far account for only about $10 \%$ of the overall heritability of T2D. In addition, how these novel susceptibility loci correlate with the pathophysiology of the disease remains largely unknown. This review covers the major genetic studies on the risk of T2D based on ethnicity and briefly discusses the potential mechanisms and clinical utility of the genetic information underlying T2D.

\section{Introduction}

The prevalence of type 2 diabetes (T2D) is rising rapidly owing to increased economic growth and lifestyle changes in both developed and developing countries. According to a recent report, the number of diabetics is estimated to reach 439 million by 2030 worldwide [1]. Therefore, strategies to prevent and treat diabetes are urgently needed in order to stem this global pandemic. It is well known that T2D is caused by $\beta$-cell dysfunction and/or insulin resistance, which is promoted by multifactorial genetic or environmental factors. Over the years, linkage analysis, candidate gene approach, large-scale association studies, and genome-wide association studies (GWAS) have successfully identified multiple genes that contribute to T2D susceptibility. Combined analyses of these loci, such as construction of genetic risk scores, have contributed significantly to the prediction of T2D diabetes and thus facilitated the adoption of early diagnosis and preventative strategies to reduce this growing disease burden [2-5].

Pharmacogenomics is an emerging discipline that highlights the role of inherited and acquired genetic variations in drug response and which is beneficial for appropriate selection of antidiabetic drugs [6]. So far, pharmacogenomics has proven to be valuable in guiding therapeutic choices in maturity onset diabetes in the young (MODY) and in neonatal diabetes; however, its extension to T2D still needs detailed studies [7]. The present review summarizes recent genetic research on T2D in both ethnic and chronologic contexts and briefly discusses the potential mechanisms and clinical utilities of genetic information in T2D.

\section{Advances in Type 2 Diabetes Genetic Research}

Linkage analysis, candidate gene approach, large-scale association studies, and GWAS have identified approximately 70 loci conferring susceptibility to T2D. Among them, 45 loci were identified in European populations (Table 1), and the other 29 loci were identified in Asian populations, especially in East and South Asians (Tables 2 and 3). The immediate benefit derived from these findings was the better understanding of the pathophysiology of T2D. 
TABLE 1: European-derived susceptibility loci for type 2 diabetes.

\begin{tabular}{|c|c|c|c|c|c|c|c|c|c|}
\hline & Locus & SNP & Chr. & Position & $\begin{array}{c}\text { Allele } \\
\text { (risk/other) }\end{array}$ & RAF $^{*}$ & OR & $\begin{array}{c}\text { Probable } \\
\text { mechanism }\end{array}$ & \\
\hline 2000 & $P P A R \gamma[8]$ & rs1801282 & 3 & 12368125 & $\mathrm{C} / \mathrm{G}$ & 0.92 & 1.14 & Insulin action & $\begin{array}{c}\text { Candidate and } \\
\text { large-scale } \\
\text { association study }\end{array}$ \\
\hline 2003 & KCNJ11 [9] & rs5219 & 11 & 17366148 & $\mathrm{~T} / \mathrm{C}$ & 0.5 & 1.14 & $\beta$-Cell function & $\begin{array}{c}\text { Candidate and } \\
\text { large-scale } \\
\text { association study }\end{array}$ \\
\hline 2006 & TCF7L2 [10] & rs7903146 & 10 & 114748339 & $\mathrm{~T} / \mathrm{C}$ & 0.25 & 1.37 & $\beta$-Cell function & $\begin{array}{c}\text { Candidate and } \\
\text { large-scale } \\
\text { association study }\end{array}$ \\
\hline 2007 & WFS1 [11] & rs10010131 & 4 & 6343816 & $\mathrm{G} / \mathrm{A}$ & 0.6 & 1.11 & $\beta$-Cell function & $\begin{array}{c}\text { Candidate and } \\
\text { large-scale } \\
\text { association study }\end{array}$ \\
\hline 2007 & $H N F 1 B[12]$ & rs4430796 & 17 & rs4430796 & $\mathrm{A} / \mathrm{G}$ & 0.47 & 1.1 & $\beta$-Cell function & $\begin{array}{c}\text { Candidate and } \\
\text { large-scale } \\
\text { association study }\end{array}$ \\
\hline 2007 & $I G F 2 B P 2[13-15]$ & rs4402960 & 3 & 186994381 & $\mathrm{~T} / \mathrm{G}$ & 0.29 & 1.14 & $\beta$-Cell function & GWAS \\
\hline 2007 & CDKN2A-CDKN2B [13-15] & rs10811661 & 9 & rs10811661 & $\mathrm{T} / \mathrm{C}$ & 0.79 & 1.2 & $\beta$-Cell function & GWAS \\
\hline 2007 & CDKAL1 [13-16] & rs10946398 & 6 & 20769013 & $\mathrm{C} / \mathrm{A}$ & 0.31 & 1.12 & $\beta$-Cell function & GWAS \\
\hline 2007 & SLC30A8 [17] & rs13266634 & 8 & 118253964 & $\mathrm{C} / \mathrm{T}$ & 0.75 & 1.12 & $\beta$-Cell function & GWAS \\
\hline 2007 & HHEX/IDE [17] & rs1111875 & 10 & 94452862 & $\mathrm{C} / \mathrm{T}$ & 0.56 & 1.13 & $\beta$-Cell function & GWAS \\
\hline 2007 & FTO $[13,15,18]$ & rs8050136 & 16 & rs8050136 & $\mathrm{A} / \mathrm{C}$ & 0.45 & 1.17 & Obesity & GWAS \\
\hline 2008 & NOTCH2 [19] & rs10923931 & 1 & 120230001 & $\mathrm{~T} / \mathrm{G}$ & 0.106 & 1.13 & Unknown & GWAS \\
\hline 2008 & ADAMTS9 [19] & rs4607103 & 3 & 64686944 & $\mathrm{C} / \mathrm{T}$ & 0.761 & 1.09 & Insulin action & GWAS \\
\hline 2008 & THADA [19] & rs7578597 & 2 & 43644474 & $\mathrm{~T} / \mathrm{C}$ & 0.902 & 1.15 & $\beta$-Cell function & GWAS \\
\hline 2008 & TSPAN8/LGR5 [19] & rs7961581 & 12 & 69949369 & $\mathrm{C} / \mathrm{T}$ & 0.269 & 1.09 & $\beta$-Cell function & GWAS \\
\hline 2008 & CDC123/CAMK1D [19] & rs12779790 & 10 & 12368016 & $\mathrm{G} / \mathrm{A}$ & 0.183 & 1.11 & $\beta$-Cell function & GWAS \\
\hline 2008 & $J A Z F 1[19]$ & rs864745 & 7 & 28147081 & $\mathrm{~T} / \mathrm{C}$ & 0.501 & 1.1 & $\beta$-Cell function & GWAS \\
\hline 2009 & MTNR1B [20] & rs1387153 & 11 & 92313476 & $\mathrm{~T} / \mathrm{C}$ & 0.283 & 1.15 & $\beta$-Cell function & GWAS \\
\hline 2009 & $\operatorname{IRS} 1[21]$ & rs2943641 & 2 & 226801989 & $\mathrm{C} / \mathrm{T}$ & 0.633 & 1.19 & Insulin action & GWAS \\
\hline 2010 & DGKB/TMEM195 [22] & rs2191349 & 7 & 15030834 & $\mathrm{~T} / \mathrm{G}$ & 0.333 & 1.06 & $\beta$-Cell function & GWAS \\
\hline 2010 & GCKR [22] & rs780094 & 2 & 27594741 & $\mathrm{C} / \mathrm{T}$ & 0.394 & 1.06 & Insulin action & GWAS \\
\hline 2010 & GCK [22] & rs4607517 & 7 & 44202193 & $\mathrm{~A} / \mathrm{G}$ & 0.195 & 1.07 & $\beta$-Cell function & GWAS \\
\hline 2010 & PROX1 [22] & rs340874 & 1 & 212225879 & $\mathrm{C} / \mathrm{T}$ & 0.492 & 1.07 & $\beta$-Cell function & GWAS \\
\hline 2010 & $A D C Y 5[22]$ & rs11708067 & 3 & 124548468 & $\mathrm{~A} / \mathrm{G}$ & 0.226 & 1.12 & $\beta$-Cell function & GWAS \\
\hline 2010 & RBMS1/ITGB6 [23] & rs7593730 & 2 & 160879700 & $\mathrm{C} / \mathrm{T}$ & 0.23 & 0.9 & Insulin action & GWAS \\
\hline 2010 & KCNQ1 [24] & rs231362 & 11 & 2648047 & G/A & 0.52 & 1.08 & $\beta$-Cell function & GWAS \\
\hline 2010 & DUSP9 [24] & rs5945326 & $\mathrm{X}$ & 152553116 & $\mathrm{~A} / \mathrm{G}$ & 0.79 & 1.27 & Insulin action & GWAS \\
\hline 2010 & $P R C 1[24]$ & rs 8042680 & 15 & 89322341 & $\mathrm{~A} / \mathrm{C}$ & 0.22 & 1.07 & Unknown & GWAS \\
\hline 2010 & ZFAND6 [24] & rs11634397 & 15 & 78219277 & $\mathrm{G} / \mathrm{A}$ & 0.6 & 1.06 & Unknown & GWAS \\
\hline 2010 & HNF1A [24] & rs7957197 & 12 & 119945069 & $\mathrm{~T} / \mathrm{A}$ & 0.85 & 1.07 & Unknown & GWAS \\
\hline 2010 & HMGA2 [24] & rs1531343 & 12 & 64461161 & $\mathrm{C} / \mathrm{G}$ & 0.1 & 1.1 & Insulin action & GWAS \\
\hline 2010 & CENTD2 [24] & rs1552224 & 11 & 72110746 & $\mathrm{~A} / \mathrm{C}$ & 0.88 & 1.14 & $\beta$-Cell function & GWAS \\
\hline 2010 & CHCHD9 [24] & rs13292136 & 9 & 81141948 & $\mathrm{C} / \mathrm{T}$ & 0.93 & 1.11 & Unknown & GWAS \\
\hline 2010 & TP53INP1 [24] & rs896854 & 8 & 96029687 & $\mathrm{~T} / \mathrm{C}$ & 0.48 & 1.06 & Unknown & GWAS \\
\hline 2010 & KLF14 [24] & rs972283 & 7 & 130117394 & $\mathrm{G} / \mathrm{A}$ & 0.55 & 1.07 & Insulin action & GWAS \\
\hline 2010 & ZBED3 [24] & rs 4457053 & 5 & 76460705 & $\mathrm{G} / \mathrm{A}$ & 0.26 & 1.08 & Unknown & GWAS \\
\hline 2010 & BCL11A [24] & rs243021 & 2 & 60438323 & $\mathrm{~A} / \mathrm{G}$ & 0.46 & 1.08 & Unknown & GWAS \\
\hline
\end{tabular}


TABLE 1: Continued.

\begin{tabular}{lccccccccc}
\hline & Locus & SNP & Chr. & Position & $\begin{array}{c}\text { Allele } \\
\text { (risk/other) }\end{array}$ & RAF* & OR & $\begin{array}{c}\text { Probable } \\
\text { mechanism }\end{array}$ \\
\hline 2012 & HMG20A [25] & rs7177055 & 15 & $75,619,817$ & A/G & 0.68 & 1.08 & Unknown \\
2012 & GRB14 [25] & rs13389219 & 2 & $165,237,122$ & C/T & 0.6 & 1.07 & Insulin action & GWAS \\
2012 & ZMIZ1 [25] & rs12571751 & 10 & $80,612,637$ & A/G & 0.52 & 1.08 & Unknown & GWAS \\
2012 & ANK1 [25] & rs516946 & 8 & $41,638,405$ & C/T & 0.76 & 1.09 & $\beta$-cell function & GWAS \\
2012 & KLHDC5 [25] & rs10842994 & 12 & $27,856,417$ & C/T & 0.8 & 1.1 & Unknown & GWAS \\
2012 & TLE1 [25] & rs2796441 & 9 & $83,498,768$ & G/A & 0.57 & 1.07 & Unknown & GWAS \\
2012 & ANKRD55 [25] & rs459193 & 5 & $55,842,508$ & G/A & 0.7 & 1.08 & Insulin action & GWAS \\
2012 & CILP2 [25] & rs10401969 & 19 & $19,268,718$ & C/T & 0.08 & 1.13 & Unknown & GWAS \\
2012 & MC4R [25] & rs12970134 & 18 & $56,035,730$ & A/G & 0.27 & 1.08 & Unknown & GWAS \\
2012 & BCAR1 [25] & rs7202877 & 16 & $73,804,746$ & T/G & 0.89 & 1.12 & $\beta$-Cell function & GWAS \\
\hline
\end{tabular}

${ }^{*}$ Data were derived from HapMap East Asian or original studies. Position is given for NCBI Build 36.

SNP: single nucleotide polymorphism; Chr.: chromosome; RAF: risk allele frequency; OR: odds ratio.

TABLE 2: Type 2 diabetes susceptibility loci identified in East Asians.

\begin{tabular}{|c|c|c|c|c|c|c|c|c|c|}
\hline & Locus & SNP & Chr. & Position & $\begin{array}{c}\text { Allele } \\
\text { (risk/other) }\end{array}$ & $\mathrm{RAF}^{*}$ & OR & $\begin{array}{c}\text { Probable } \\
\text { mechanism }\end{array}$ & \\
\hline 2009 & KCNQ1 [26] & rs2237892 & 11 & 2796327 & $\mathrm{C} / \mathrm{T}$ & 0.683 & 1.43 & $\beta$-Cell function & GWAS \\
\hline 2010 & $U B E 2 E 2[27]$ & rs7612463 & 3 & 23311454 & $\mathrm{~A} / \mathrm{C}$ & 0.134 & 1.19 & Unknown & GWAS \\
\hline 2010 & $C 2 C D 4 A-C 2 C D 4 B[27]$ & rs7172432 & 15 & 60183681 & $\mathrm{~A} / \mathrm{G}$ & 0.42 & 1.13 & Unknown & GWAS \\
\hline 2010 & SPRY2 [28] & rs1359790 & 13 & 79615157 & $\mathrm{G} / \mathrm{A}$ & 0.273 & 1.15 & Unknown & GWAS \\
\hline 2010 & CDC123/CAM K1D [28] & rs10906115 & 10 & 12355003 & $\mathrm{~A} / \mathrm{G}$ & 0.561 & 1.13 & Unknown & GWAS \\
\hline 2010 & SRR [29] & rs391300 & 17 & 2163008 & G/A & 0.367 & 1.28 & $\beta$-Cell function & GWAS \\
\hline 2010 & PTPRD [29] & rs17584499 & 9 & 8869118 & $\mathrm{~T} / \mathrm{C}$ & 0.226 & 1.57 & Insulin action & GWAS \\
\hline 2011 & MAEA [30] & rs6815464 & 4 & 1299901 & $\mathrm{C} / \mathrm{G}$ & 0.640 & 1.13 & Unknown & GWAS \\
\hline 2011 & PSMD6 [30] & rs831571 & 3 & 64023337 & $\mathrm{C} / \mathrm{T}$ & 0.688 & 1.09 & Unknown & GWAS \\
\hline 2011 & ZFAND3 [30] & rs9470794 & 6 & 38214822 & $\mathrm{C} / \mathrm{T}$ & 0.203 & 1.12 & Unknown & GWAS \\
\hline 2011 & GCC1-PAX4 [30] & rs6467136 & 7 & 126952194 & G/A & 0.182 & 1.11 & Unknown & GWAS \\
\hline 2011 & KCNK16 [30] & rs1535500 & 6 & 39392028 & $\mathrm{~T} / \mathrm{G}$ & 0.398 & 1.08 & $\beta$-Cell function & GWAS \\
\hline 2011 & $P E P D[30]$ & rs3786897 & 19 & 38584848 & $\mathrm{~A} / \mathrm{G}$ & 0.547 & 1.1 & Unknown & GWAS \\
\hline 2011 & FITM2-R3HD [30] & rs6017317 & 20 & 42380380 & $\mathrm{G} / \mathrm{T}$ & 0.545 & 1.09 & $\beta$-Cell function & GWAS \\
\hline 2011 & GLIS3 [30] & rs7041847 & 9 & 4277466 & $\mathrm{~A} / \mathrm{G}$ & 0.529 & 1.1 & $\beta$-Cell function & GWAS \\
\hline 2012 & $A N K 1[31]$ & rs515071 & 8 & $41,638,405$ & $\mathrm{C} / \mathrm{T}$ & 0.8 & 1.18 & Unknown & GWAS \\
\hline 2013 & GRK5 [32] & rs10886471 & 10 & 121139393 & $\mathrm{C} / \mathrm{T}$ & 0.756 & 1.12 & Insulin action & GWAS \\
\hline 2013 & RASGRP1 [32] & rs7403531 & 15 & 36610197 & $\mathrm{~T} / \mathrm{C}$ & 0.317 & 1.1 & $\beta$-Cell function & GWAS \\
\hline 2013 & PAX4 [33] & rs10229583 & 7 & 127034139 & $\mathrm{G} / \mathrm{A}$ & 0.829 & 1.18 & Unknown & GWAS \\
\hline 2013 & MIR129-LEP [34] & rs791595 & 7 & 127650038 & $\mathrm{~A} / \mathrm{G}$ & 0.08 & 1.17 & Unknown & GWAS \\
\hline 2013 & SLC16A13 [34] & rs312457 & 17 & 6881117 & G/A & 0.078 & 1.2 & Unknown & GWAS \\
\hline 2013 & GPSM1 [34] & rs11787792 & 9 & 138371969 & $\mathrm{~A} / \mathrm{G}$ & 0.874 & 1.15 & Unknown & GWAS \\
\hline
\end{tabular}

* Data were derived from HapMap East Asian or original studies. Position is given for NCBI Build 36.

SNP: single nucleotide polymorphism; Chr.: chromosome; RAF: risk allele frequency; OR: odds ratio.

\subsection{Genetics of Type 2 Diabetes in European Populations}

2.1.1. Linkage Analysis, Candidate Gene Approach, and LargeScale Association Studies. Linkage analysis has proved to be valuable in the exploration of genetic factors of monogenic diseases, such as MODY, neonatal mitochondrial diabetes, insulin resistance, and Wolfram syndromes [38-40]. However, it has not been particularly useful in identifying the genetic factors for common forms of T2D. Over the years, linkage studies have reported many predisposing associations with chromosomal regions for T2D, including segments in chromosomes 5 and 10, and have identified putative, causative 
TABLE 3: Type 2 diabetes susceptibility loci identified in South Asians.

\begin{tabular}{|c|c|c|c|c|c|c|c|c|c|}
\hline & Locus & SNP & Chr. & Position & $\begin{array}{c}\text { Allele } \\
\text { (risk/other) }\end{array}$ & RAF $^{*}$ & OR & Probable mechanism & \\
\hline 2011 & ST6GAL1 [35] & rs16861329 & 3 & 188149155 & $\mathrm{G} / \mathrm{A}$ & 0.86 & 1.09 & $\beta$-Cell function & $\overline{\text { GWAS }}$ \\
\hline 2011 & HNF4A [35] & rs4812829 & 20 & 42422681 & $\mathrm{~A} / \mathrm{G}$ & 0.29 & 1.09 & $\beta$-Cell function & GWAS \\
\hline 2011 & VPS26A [35] & rs1802295 & 10 & 70601480 & $\mathrm{~A} / \mathrm{G}$ & 0.26 & 1.08 & Unknown & GWAS \\
\hline 2011 & AP3S2 [35] & rs2028299 & 15 & 88175261 & $\mathrm{C} / \mathrm{A}$ & 0.31 & 1.1 & Unknown & GWAS \\
\hline 2011 & $H M G 20 A[35]$ & rs7178572 & 15 & 75534245 & $\mathrm{G} / \mathrm{A}$ & 0.52 & 1.09 & Unknown & GWAS \\
\hline 2011 & GRB14 [35] & rs3923113 & 2 & 165210095 & $\mathrm{~A} / \mathrm{C}$ & 0.74 & 1.09 & Insulin action & GWAS \\
\hline 2013 & TMEM163 [36] & rs998451 & 2 & 135145758 & G/A & 1 & 1.56 & $\beta$-Cell function & GWAS \\
\hline 2013 & SGCG [37] & rs9552911 & 13 & 22762657 & $\mathrm{~A} / \mathrm{G}$ & 0.07 & 0.67 & Unknown & GWAS \\
\hline
\end{tabular}

* Data were derived from HapMap East Asian or original studies. Position is given for NCBI Build 36.

SNP: single nucleotide polymorphism; Chr.: chromosome; RAF: risk allele frequency; OR: odds ratio.

genetic variants in CAPN10 [41], ENPP1 [42], HNF4A [43, 44], and $A C D C$ (also called $A D I P O Q$ ) [45], but most of the findings from these reports could not be replicated.

During the past several decades, only a few loci conferring risk of T2D were identified through candidate gene approach with PPAR $\gamma$ Pro12Ala polymorphism being the first reported locus [8]. PPAR $\gamma$ is a transcription factor that plays a pivotal role in adipocyte differentiation. It was reported that PPAR $\gamma$ Prol2Ala variant was associated with increased insulin sensitivity in the general population and thus may protect an individual from T2D [46]. The KCNJ11 (potassium inwardly rectifying channel subfamily J, member 11) encodes potassium inwardly rectifier 6.2 subunit (Kir6.2) of the ATPsensitive potassium $\left(\mathrm{K}_{\mathrm{ATP}}\right)$ channel, which has an impact on glucose-dependent insulin secretion in pancreatic $\beta$-cells [9]. The E23K variant in this gene demonstrated a robust association with T2D using the candidate gene approach [9]. WFS1 and HNF1B were also uncovered as established genes associated with T2D [11, 12]. WFS1 encodes wolframin, a membrane glycoprotein that maintains calcium homeostasis of the endoplasmic reticulum. Rare mutations in WFS1 cause Wolfram syndrome, which is characterized by a significant $\beta$-cell loss as a result of enhanced endoplasmic reticulum stress [47-49]. HNF1B encodes hepatocyte nuclear factor 1 homeobox $\mathrm{B}$, which is a liver-specific factor of the homeoboxcontaining basic helix-turn-helix family. Mutation of this gene was demonstrated to cause MODY5 [38].

In 2006, a large-scale association study identified TCF7L2 as an important genetic factor for T2D in Icelandic individuals [10]. This discovery was a significant breakthrough as this association was then widely confirmed in populations of European origin and other ethnic groups, such as Japanese and American individuals [50-57]. Therefore, TCF7L2 was regarded as the most significant $\mathrm{T} 2 \mathrm{D}$ susceptibility gene identified to date.

2.1.2. Genome-Wide Association Study (GWAS). With the advent of GWAS, exploration of the genetic basis for T2D susceptibility has made significant breakthroughs. In 2007, the results of five genome-wide association studies were published. These studies increased the number of confirmed T2D susceptibility loci to nine (PPAR $\gamma, K C N J 11, T C F 7 L 2$,
CDKAL1, CDKN2A/B, IGF2BP2, HHEX/IDE, FTO, and SLC30A8) [13-18]. Except for PPAR $\gamma$ and FTO, which mainly affect insulin sensitivity, all the other genes may affect $\beta$ cell function, although the exact mechanisms remain largely unknown [16]. HHEX, which is located on chromosome $10 \mathrm{q}$, is a member of the homeobox family and encodes a transcription factor that maybe involved in Wnt signaling [58]. Nevertheless, these studies established the utility of GWAS approach in elucidating complex genetic traits.

In 2008 , to increase the power of identifying variants with modest effects, a meta-analysis of three GWAS, including Diabetes Genetics Initiative (DGI), Finland-United States Investigation of NIDDM Genetics (FUSION), and Wellcome Trust Case Control Consortium (WTCCC), were conducted. This study detected at least six previously unknown loci that reached genome-wide significance for association with T2D $\left(P<5 \times 10^{-8}\right)$, with the loci being JAZF1, CDC123-CAMK1D, TSPAN8-LGR5, THADA, ADAMTS9, and NOTCH2 [19]. Genetic variants in JAZF1, CDC123-CAMK1D, TSPAN8$L G R 5$, and THADA have been reported to affect pancreatic $\beta$-cell functions $[59,60]$.

In 2009, a novel genetic variant rs2943641, which is located adjacent to the insulin receptor substrate 1 gene (IRS1), was shown to have a significant association with insulin resistance and hyperinsulinemia and further studies also showed that this variant is implicated in reduced basal IRS1 protein level and decreased IRS1-associated phosphatidylinositol-3-OH kinase activity in human skeletal muscle biopsies [21]. In the same year, a variant near MTNR1B was found to be associated with increased fasting plasma glucose level and higher risk of T2D (odds ratio $=1.15,95 \% \mathrm{CI}$ $=1.08-1.22, P=6.3 \times 10^{-5}$ ) [20]. Ten GWAS involving a total of 36,610 individuals of European descent and a meta-analysis of 13 case-control studies replicated this result and found that risk alleles in this gene are associated with reduced $\beta$ cell function as measured by homeostasis model assessment (HOMA- $\beta, P=1.1 \times 10^{-15}$ ) [61].

In 2010, a meta-analysis of 21 genome-wide association studies performed by Dupuis and colleagues identified ADCY5, PROX1, GCK, GCKR, and DGKB/TMEM195 as new genetic loci for T2D susceptibility [22]. Among these loci, DGKB/TMEM195, GCK, PROX1, and ADCY5 mainly affect 
$\beta$-cell functions, whereas the locus mapped in GCKR shows a primary effect on insulin action [22]. In the same year, another genome-wide association study by Qi and colleagues discovered new variants near RBMS1 and ITGB6 genes at $2 \mathrm{q} 24$, and these variants were found to affect glucose metabolism and insulin resistance [23]. In addition, an expanded meta-analysis of existing GWAS by Voight and colleagues identified 12 new signals with a combined $P<$ $5 \times 10^{-8}$, including BCL11A, ZBED3, KLF14, TP53INP1, TLE4, CENTD2, HMGA2, HNF1A, PRC1, ZFAND6, DUSP9, and KCNQ1 [24]. HNF1A was previously recognized as the causal gene of MODY3 [62] and also harbored the common variant (G319S) that contributes to early-onset T2D [63, 64]. DUSP9, mapped on chromosome $\mathrm{X}$, encodes a member of the family of mitogen-activated protein kinase phosphatase 4, MKP4, which is important in cell cycle regulation and plays pivotal roles in regulating insulin action [65-67].

In 2012, a meta-analysis conducted by Morris and colleagues identified additional ten previously unreported T2D susceptible loci, including BCAR1, MC4R, CILP2, ANKRD55, TLE1, KLHDC5, MGC21675, ANK1, ZMIZ1, and GRB14 [25]. To assess the potential function of these loci, OGTT was employed to test insulin release and insulin sensitivity. ANK1 was found to be associated with insulinogenic and disposition indices, indicating that this gene probably had an effect on insulin secretion [68]. In this study, GRB14 and AKNRD55 were associated with decreased Matsuda index, an index of insulin sensitivity [68].

As described above, genetic studies of T2D in European populations have made significant progress in our understanding of T2D susceptibility. However, existing data can only provide partial explanation for the heritability of T2D. It is well known that discrepancies exist in allelic frequencies and effect sizes in different ethnic groups. It is, therefore, important to understand whether these variants are also applicable to other ethnic populations.

2.2. Genetics of T2D in East Asians. Epidemiological studies have documented consistent increases in the prevalence of diabetes in Asia, especially in China, with diabetes prevalence having increased from $2.6 \%$ in 2000 to $9.7 \%$ in 2010 [69]. However, our understanding of the genetic basis of T2D in East Asia remains limited. It is therefore imperative to identify specific genes associated with this disease in East Asians.

In 2008, two papers provided the first reports of GWAS for T2D in East Asian populations and ascertained KCNQ1 as a new susceptibility locus [70,71]. KCNQ1 encodes the pore-forming $\alpha$-subunit of the voltage-gated $\mathrm{K}^{+}$channel (KvLQT1), which is expressed mainly in the heart and pancreas. Its association with T2D was further replicated in Korean [72], Chinese [26], and Singaporean [73] populations, as well as individuals of European descent [70]. Therefore, KCNQ1 is regarded as the most significant locus for T2D in East Asians. This genetic variant is implicated in insulin secretion, which may be the explanation for its association with T2D $[73,74]$.
In 2010, another GWAS conducted in a Japanese group identified two new loci in UBE2E2 and C2CD4A-C2CD4B. Genetic variants in $C 2 C D 4 A-C 2 C D 4 B$ were then validated in European populations [27]. When the GWAS reports sprung up in East Asians, Chinese investigators performed their first GWAS in the Han Chinese residing in Taiwan and identified two new susceptible loci for T2D in PTPRD (protein tyrosine phosphatase receptor type D) and $S R R$ (serine racemase) [29]. PTPRD is a protein tyrosine phosphatase and may play a role in the pathogenesis of T2D through increased insulin resistance [75]. SRR encodes a serine racemase that synthesizes $\mathrm{D}$-serine from L-serine and which confers risk for T2D via the glutamate signaling pathway $[76,77]$. In the same year, a fast-track, multiple-stage study conducted in Han Chinese population by Shu and colleagues discovered a novel genetic susceptibility locus rs1359790, at $13 q 31.1$ for T2D, and this variant was also validated in European Americans, Koreans, and Singapore Chinese [28].

In 2011, in order to identify additional genes in East Asians, Cho and colleagues carried out a meta-analysis of three-stage GWAS in populations of East Asian descent. Compelling evidence for association with T2D of eight novel loci was demonstrated by this study. All of these loci are mapped in or near GLIS3, PEPD, FITM2-R3HDML-HNF4A, KCNK16, MAEA, GCC1-PAX4, PSMD6, and ZFAND [30].

In 2012, another GWAS in Japanese populations revealed that rs515071 in ANK1 was associated with T2D at the genome-wide significance level [31]. ANK1, which encodes a member of the ankyrin family, is also reported to be associated with impaired insulin secretion and abnormal level of $\mathrm{HbA}_{1 \mathrm{c}}[68,78]$. In addition, GWAS in Beijing and Shanghai populations added two new loci to the list, GRK5 and RASGRP1, and the association signal for GRK5 seems to be specific to East Asians [32]. GRK5 is regarded as a positive regulator of insulin sensitivity and this protein is a potential therapeutic target for the treatment of insulin resistance [79].

In 2013, a novel variant rs10229583 at 7q32 near PAX4 was identified in a meta-analysis of three GWAS from Southern Han Chinese descents [33]. As a member of the paired box family of transcription factors, PAX4 plays a critical role in pancreatic $\beta$-cell development and $\beta$-cell functions [80]. Further three new predisposing loci, MIR129-LEP, GPSM1, and SLC16A13, with genome-wide significance for T2D were identified [34]. Rs791595 is located between MIR129-1 and $L E P$. The coding product of $L E P$, leptin, is closely related to body weight regulation and its deficiency in mice and human causes morbid obesity and diabetes, while the role of MIR129 in diabetes remains unknown [81].

Besides these newly identified loci, some susceptible genes identified in Caucasians were also replicated in East Asians, such as PPAR $\gamma, K C N J 11$, TCF2, TCF7L2, CDKAL1, CDKN2A-CDKN2B, IDE-KIF11-HHEX, IGF2BP2, MTNR1B, SLC30A8, KCNQ1, CDC123, GLIS3, HNF1B, and DUSP9 [32, 82-93].

Together, all these T2D risk loci, initially identified or replicated in East Asians, provide new perspectives on the etiology of T2D and uncover the need for further studies to explore additional loci with strong effects on T2D. 
2.3. Genetics of T2D in South Asians. South Asia, with more than a quarter of the world's population, harbors the highest number of patients suffering from T2D [94]. Currently, the number of diabetic patients is reaching 62.4 million, and the number of prediabetic individuals is reaching 77.2 million [95]. Compared to European populations, South Asians are at a fourfold higher risk of T2D $[96,97]$. Therefore, significant efforts should be made to identify common genetic variants underlying the T2D risk in individuals of South Asian ancestry.

In 2011, a GWAS in South Asians identified six novel loci harboring disease-predisposing variants, including GRB14, ST6GAL1, VPS26A, HMG20A, AP3S2, and HNF4A. Single nucleotide polymorphisms (SNPs) at GRB14 were associated with insulin sensitivity and SNPs at ST6GAL1 and HNF4A were associated with pancreatic $\beta$-cell function [35].

In 2013, a GWAS performed in Indians identified TMEM163 on chromosome $2 \mathrm{q} 21$ as a new signal for T2D. TMEM163 encodes a putative vesicular transporter in nerve terminals and shows a plausible effect on T2D by impairing insulin secretion [36]. Concurrently, a novel locus at 13q12 in the SGCG gene was identified to confer T2D susceptibility in Punjabi Sikhs from Northern India. This association demonstrated excellent consistency across the three Sikh samples, but no significant association was observed in a large East Asian replication study, indicating that the detected locus is specific to the Indian Punjabi Sikh population [37].

In consideration of India's complex demographic history, cultural diversity, differences in risk allele frequency, and pattern of linkage disequilibrium existing between European and South Asian populations, large replication studies were conducted to evaluate the contribution of European-derived loci in South Asian populations. SNPs in or near PPARG, KCNJ11, TCF7L2, SLC30A8, HHEX, CDKN2A/B, IGF2BP2, CDKAL1, FTO, KCNQ1, JAZF1, IRS1, KLF14, CHCHD9, and DUSP9 displayed significant associations with T2D in Pakistani populations, with similar effect sizes as those seen in European populations [98-102].

2.4. Genetics of Type 2 Diabetes in Other Populations. The discovery of new susceptibility loci for T2D by GWAS in different ethnic groups emphasizes the need to conduct more GWAS based on ethnic background. In addition to European and Asian populations, researchers also conducted studies in Pima Indians and Mexican Americans aimed at identifying new risk loci.

In Pima Indians, a few genes have been reported to confer risk of T2D. In 2007, researchers found that variants within ARHGEF11 nominally increased the risk of T2D, possibly as a result of increased insulin resistance [103]. In 2008, variation within PCLO was confirmed to have a modest effect on earlyonset T2D, possibly by reduction of insulin action [104]. In 2010, $A C A D 10$ variation was found to increase T2D risk by impairing insulin sensitivity via abnormal lipid oxidation [105]. Soon afterwards, an ASK1 variant was identified to confer susceptibility to T2D by decreasing insulin sensitivity owing to reduced ASK1 expression in skeletal muscle [106]. However, a replication study, which genotyped SNPs mapped in CDKAL, SLC30A8, HHEX, EXT2, IGF2BP2, LOC387761, and FTO previously associated with T2D in Caucasians, did not provide any evidence for association with T2D or obesity among full-heritage Pima Indians. Instead, they found that CDKAL1, HHEX, and EXT2 were evidently associated with either insulin secretion or insulin action in Pima Indians with normal glucose tolerance [107].

Similarly, analysis of T2D risk genes in Mexican American populations had identified several novel candidate loci for T2D, such as rs979752 and rs10500641 near UBQLNL and OR52H1 on chromosome 11, rs2773080 and rs3922812 in or near RALGPS2 on chromosome 1, and rs1509957 near EGR2 on chromosome 10 [108]. In 2011, the largest GWAS and metaanalysis of T2D in Mexican populations identified 49 SNPs in eight gene regions (PER3, PARD3B, EPHA4, TOMM7, PTPRD, HNT, LOC729993, and IL34) and six intergenic regions with an unadjusted $P$ value $<1 \times 10^{-5}$ [109]. In consideration of the fact that all the above loci did not reach genome-wide significance $\left(P<5 \times 10^{-8}\right)$, Williams and colleagues analyzed 9.2 million SNPs in 8,214 Mexicans and other Latin Americans and identified a novel locus associated with T2D spanning the solute carriers SLC16A11 $\left(P=3.9 \times 10^{-13}\right.$; odds ratio $\left.(\mathrm{OR})=1.29\right)$. They observed that SLC16A11 mainly localizes with the endoplasmic reticulum membrane protein, calnexin, in liver, salivary gland, and thyroid. Importantly, overexpression of SLC16A11 in HeLa cells resulted in substantial increases in triacylglycerol, suggesting that SLC16A11 may have a role in hepatic lipid metabolism $[16,110]$. Nevertheless, the role of all these risk loci in the pathogenesis of diabetes remains unclear and needs further investigations.

\section{Correlation of the Susceptibility Loci with the Pathogenesis of T2D}

With the large number of aforementioned genetic loci susceptible to $\mathrm{T} 2 \mathrm{D}$, the question pertains to how they participate in the pathogenesis of T2D. A great number of studies have suggested that genetic variants in or near KCNJ11, TCF7L2, WFS1, HNF1B, IGF2BP2, CDKN2ACDKN2B, CDKAL1, SLC30A8, HHEX/IDE, KCNQ1, THADA, TSPAN8/LGR5, CDC123/CAMK1D, JAZF1, MTNR1B, DGKB/TMEM195, GCK, PROX1, ADCY5, SRR, CENTD2, ST6GAL1, HNF4A, KCNK16, FITM2-R3HDML-HNF4A, GLIS3, GRB14, ANK1, BCAR1, RASGRP1, and TMEM163 may confer T2D risk through impaired $\beta$-cell function $[16,24$, 44, 68, 111-114], whereas PPAR $\gamma$, ADAMTS9, IRS1, GCKR, RBMS1/ITGB6, PTPRD, DUSP9, HMGA2, KLF14, GRB14, $A N K R D 55$, and GRK5 have an impact on insulin action [21, $24,115,116$ ] (Tables 1, 2, and 3). FTO and MC4R, previously identified genes associated with obesity, appear to confer T2D risk through their primary effects on BMI, but recent GWAS have shown that their effects on T2D were independent of BMI, though FTO may have a small but detectable influence on T2D risk through insulin action $[117,118]$.

3.1. Impact of TCF7L2 on the Risk of T2D. TCF7L2 is the most intensively studied locus for T2D risk so far. The risk 
alleles of TCF7L2 were associated with enhanced expression of this gene in human islets as well as impaired insulin secretion both in vitro and in vivo. The authors also observed an impaired incretin effect in subjects carrying risk alleles of TCF7L2 and proposed the engagement of the enteroinsular axis in T2D [119]. Dennis and colleagues then verified this result and indicated that TCF7L2 variant rs7903146 affected risk of T2D, at least in part, through modifying the effect of incretins on insulin secretion. This was not due to reduced secretion of glucose-dependent insulinotropic polypeptide (GIP) and glucagon-like peptide 1 (GLP-1), which exhibit an important physiological role in boosting insulin secretion following meals, but rather due to the effect of TCF7L2 on the sensitivity of $\beta$-cells to incretins [120]. TCF7L2 has also been linked to altered pancreatic islet morphology as exemplified by increased individual islet size and altered alpha and beta cell ratio/distribution within human islets [121]. This phenomenon is also observed in other in vivo or in vitro studies [122-124]. This further strengthened the evidence for the role of TCF7L2-associated alteration of cell types in islets in the pathogenesis of T2D.

TCF7L2 encodes the transcription factor TCF4 which is related to Wnt signaling pathway and which plays a critical role in the pathogenesis of T2D. The major effector of the canonical Wnt signaling pathway is known as $\beta$ catenin/TCF. This bipartite transcription factor is formed by free $\beta$-catenin ( $\beta$-cat) and a member of the TCF protein family, including TCF7L2 (previously known as TCF-4) [125]. GWAS have revealed the involvement of a Wnt ligand (Wnt$5 b)$, Wnt coreceptor (LRP-5), and the Wnt pathway effector TCF7L2 in the development of diabetes [126]. Several previous studies also provide evidence that the $\beta$-catenin/TCF axis participates in pancreatic cell proliferation and differentiation [127-131]. Treatment of $\beta$-cells with purified Wnt protein or activated $\beta$-catenin augmented the proliferation of these cells [132]. Intriguingly, deletion of $\beta$-catenin within the pancreatic epithelium resulted in an almost complete lack of acinar cells, whereas deletion of $\beta$-catenin specifically in differentiated acinar cells had no such effect [128], suggesting that the TCF7L2-related Wnt signaling mainly perturbs pancreatic growth but not pancreatic function. However, deletion of islet TCF7L2 expression from $\beta$-cells did not show any demonstrable effects on glucose-stimulated insulin secretion (GSIS) in adult mice, whereas manipulating TCF7L2 levels in the liver caused hypoglycemia and reduced hepatic glucose production [133]. In concordance with these results, risk alleles in TCF7L2 were associated with hepatic but not peripheral insulin resistance and enhanced rate of hepatic glucose production in human [119]. Therefore, TCF7L2-related disruption of $\beta$-cell function is probably the indirect consequence of primary events in liver or other organs/systems.

3.2. Impact of SCL30A8 on the Risk of T2D. Besides TCF7L2, solute carrier family 30 member 8 gene (SCL30A8) has also been explored in depth. SCL30A8 encodes the isletspecific zinc transporter ZnT-8, which delivers zinc ions from cytoplasm into intracellular insulin-containing granules, and is implicated in insulin maturation and/or storage processes in $\beta$-cells [134]. Expression level of ZnT-8 was remarkably downregulated in the pancreas of $\mathrm{db} / \mathrm{db}$ and Akita mice in the early stage of diabetes [135]. Global SCL30A8 knockout mice demonstrated reduced plasma insulin, impaired GSIS, and markedly reduced islet zinc content [136]. Remarkably, both ZnT-8 knockout mice and human individuals carrying risk alleles of SLC3OA8 exhibited increased hepatic insulin clearance, with significantly increased c-peptide/insulin ratios [137]. Contrary to the previous findings, overexpression of ZnT-8 in INS-1 cells stimulated zinc accumulation and enhanced GSIS of these cells [138]. Importantly, a recent study discovered that SCL30A8 gene transcription was regulated by Pdx-1, a $\beta$-cell-enriched transcription factor, and involved in the development of islets, through an intrinsic enhancer. Restriction of Pdx-1 in pancreatic islet $\beta$-cells correlated with the induction of SCL30A8 gene and ZnT-8 protein expression [139]. Therefore, the specific pathways by which SL30A8 correlates with the pathogenesis of T2D still need further exploration.

It should be noted that a great number of low frequency variants might not be identified by GWAS owing to the required genome-wide significance level. According to the existing studies, many important loci are also obscured as a result of borderline associations. The known variants account for only a small amount of the overall estimated genetic heritability; therefore, there is still a long way to go in terms of understanding the pathogenesis of type 2 diabetes.

\section{Clinical Utility of Genetic Information: Prediction of Type 2 Diabetes}

One of most important clinical utilities of genetic information is to predict the risk of developing T2D among nondiabetic individuals. This will facilitate the early interventional strategies to prevent or delay the onset of the disease. A vast number of recent studies have constructed genetic risk score models by summing up numerous independently inherited susceptible variants for $\mathrm{T} 2 \mathrm{D}$ to evaluate the predictive ability from the current genetic information. For example, the area under the receiver operating characteristic (ROC) curves (AUCs) is used to assess discriminative accuracy of this approach. The AUC value can range from 0.5 to 1.0, where the AUC of 0.5 stands for the lack of discrimination and AUC of 1 stands for perfect discrimination. An AUC value of greater than 0.75 is considered to be clinically useful [140]. Imamura and colleagues created a genetic risk score model using 49 susceptibility alleles (GRS-49) for T2D in a Japanese population and discovered an increased level of AUC with combined GRS-49 and clinical factors (including age, sex, and BMI) compared with each individually. But the AUC value is only 0.773 , which shows a clinically modest but statistically significant effect on T2D [141]. This phenomenon is also observed in many other studies from different ethnic groups [142, 143]. Controversially, it was proposed that phenotype-based risk models are superior to models based on 20 common independently inherited diabetes risk alleles in discrimination for T2D, with the observation of only 
minimal improvement in accuracy of risk estimation when adding genotypes to phenotype-based risk models [144]. The discrepancy may result from the fact that prediction for T2D using genetic information is largely affected by age. For example, the Framingham Offspring Study conducted with 3,471 subjects followed over 34 years found out that common genetic variations appropriately reclassified younger people for T2D risk beyond clinical risk factors, but it failed in older people [145]. In addition, along with the rapid economic growth and lifestyle changes, we may underscore the role of environmental factors in the pathogenesis of T2D. A recent study suggested that the potential deleterious effect of several T2D loci may be abolished or at least attenuated by higher physical activity levels or healthy lifestyle, whereas they may be augmented by low physical activity and dietary factors that are similar to a Western dietary pattern [146]. Therefore, these inconsistencies will need further investigations.

\section{Pharmacogenomics of Type 2 Diabetes}

With the advent of GWAS, studies on the roles of inherited and acquired genetic variations in drug response have undergone an evolution from pharmacogenetics into pharmacogenomics, with a shift from the focus on individual candidate genes to GWAS [147]. Clinically, it is often observed that even patients who receive similar antidiabetic regimens demonstrate large variability in drug disposition, glycemic response, tolerability, and incidence of adverse effects [148]. This interindividual variability can be attributed to specific gene polymorphisms involved in the metabolism, transportation, and therapeutic mechanisms of oral antidiabetic drugs. Pharmacogenomics is on the agenda to explore feasible genetic testing to predict treatment outcome, so that appropriate steps could be taken to treat type 2 diabetes more efficiently.

In general, the oral antidiabetic drug (OAD) is the first line treatment for T2D after failure of lifestyle intervention. The most commonly prescribed OADs include sulfonylureas (SU), biguanides, thiazolidinediones (TZDs), glinides, and $\alpha$ glucosidase inhibitors. To date, numerous pharmacogenetic studies comparing these drugs have been conducted in populations with different ethnic backgrounds. With respect to sulfonylureas, genetic variants at multiple loci such as KCNJ11, ABCC8, IRIS1, TCF7L2, NOS1AP, KCNQ1, CDKAL1, and CAPN10 affect pharmacokinetics and/or pharmacodynamics of these drugs [149-157]. Among them, KCNJ11 encodes a major subunit of the ATP-sensitive $\mathrm{K}^{+}$channel, and $A B C C 8$ encodes a modulator of ATP-sensitive potassium channels (SUR1). They both play pivotal roles in insulin secretion and are both shown in pharmacogenomic studies to impact sulfonylureas efficacy [151, 158]. The Arg (972) IRS-1 variant is associated with increased risk for secondary failure to sulfonylurea and it is noteworthy that the genotype frequency of this variant is twice as high in patients with secondary failure to sulfonylurea compared to the diabetic patients whose blood glucose levels were well controlled with oral therapy [157]. In diabetic patients carrying risk alleles in NOS1AP gene, glibenclamide is less effective in reducing glucose levels. The increased mortality in users of sulfonylurea was also shown in this paper, reminding us of the fact that genetic variation could alter responses to T2D therapy [155]. Consistent with this notion, studies have shown that genetic variants in SLC22A1, SLC22A2, SLC47A1, SLC47A2, and ATM [159-167] were found to affect metformin efficacy. SLC22A1 encodes organic cation transporter 1 (OCT1), which participates in the transportation of metformin into hepatocytes. SLC47A1 encodes the multidrug and toxin extrusion 1 protein (MATE1), which facilitates metformin excretion from hepatocytes into bile. ATM, a gene known to be involved in DNA repair and cell cycle control, plays a role in metformin efficacy upstream of AMPK, and variation in this gene alters glycemic responses to metformin [167].

Gene polymorphisms associated with glinide (repaglinide and nateglinide) responses were mapped in $C Y P 2 C 8$, SLCO1B1, TCF7L2, CYP3A4, IGF2BP2, SLC30A8, KCNQ1, KCNJ11, NAMPT, UCP2, MDR1, NeuroD1, and PAX4 [168174]. Among them, SLCO1B1 is mainly expressed in the basolateral membrane of hepatocytes and can facilitate hepatic uptake of repaglinide [175]; polymorphisms of this gene have significant influence on the pharmacokinetics of repaglinide with reduced pharmacokinetic exposure after a single oral dose administration of $2 \mathrm{mg}$ repaglinide [176]. Thiazolidinediones, also known as glitazones, act as agonists for their molecular target, peroxisome proliferator-activated receptor- $\gamma$ (PPAR- $\gamma$ ). The direct antioxidant action of glitazones may contribute to its effect on insulin resistance [177]. Recent studies have also reported several loci involved in the pharmacogenetics of thiazolidinediones, including $P G C-1 \alpha$, resistin, adiponectin, leptin, TNF-alpha, and CYP2C8 [178183].

Pharmacogenetic research provides a means to better understand and improve pharmacotherapy. Despite all these advances in the field of pharmacogenetics, adequately designed and rigorously conducted clinical trials are still needed for guiding therapeutic decisions in T2D treatment.

\section{Conclusion}

To date, approximately 70 loci associated with T2D have been identified. Despite this excellent progress, the current knowledge from these genetic data is still not sufficient to support the clinical utility for the prediction, early identification, and prevention of diabetes. As an emerging field, pharmacogenomics aims at exploring possible molecular mechanisms of drugs and specific genetic variants associated with drug efficacy and thus can make contributions for decisions regarding drug selection, dose titration, treatment duration, and avoidance of adverse drug reactions. However, the loci identified so far explain only a small amount of the estimated heritability of type 2 diabetes and the clinical utility of genetic information is still in its preliminary stage. There is no doubt that intensive studies should be conducted to further identify T2D inheritability factors and promote the translation of novel findings from GWAS to clinical application. 


\section{Conflict of Interests}

The authors declare that there is no conflict of interests regarding the publication of this paper.

\section{Authors' Contribution}

Xue Sun and Weihui Yu contributed equally to this paper.

\section{Acknowledgments}

The authors thank all the individuals who participated in this study and are appreciative of the doctors and nurses at the Shanghai Clinical Center for Diabetes. They acknowledge Grants from NSFC (81322010), the Excellent Young Medical Expert of Shanghai (XYQ2011041), the Shanghai Talent Development Grant (2012041), and the National Young Top Talent Supporting Program.

\section{References}

[1] J. E. Shaw, R. A. Sicree, and P. Z. Zimmet, "Global estimates of the prevalence of diabetes for 2010 and 2030," Diabetes Research and Clinical Practice, vol. 87, no. 1, pp. 4-14, 2010.

[2] J. B. Meigs, P. Shrader, L. M. Sullivan et al., "Genotype score in addition to common risk factors for prediction of type 2 diabetes," The New England Journal of Medicine, vol. 359, no. 21, pp. 2208-2219, 2008.

[3] M. van Hoek, A. Dehghan, J. C. M. Witteman et al., "Predicting type 2 diabetes based on polymorphisms from genome-wide association studies: a population-based study," Diabetes, vol. 57, no. 11, pp. 3122-3128, 2008.

[4] M. C. Cornelis, L. Qi, C. Zhang et al., "Joint effects of common genetic variants on the risk for type 2 diabetes in US men and women of European ancestry," Annals of Internal Medicine, vol. 150, no. 8, pp. 541-550, 2009.

[5] V. Lyssenko, A. Jonsson, P. Almgren et al., "Clinical risk factors, DNA variants, and the development of type 2 diabetes," The New England Journal of Medicine, vol. 359, no. 21, pp. 2220-2232, 2008.

[6] V. G. Manolopoulos, G. Ragia, and A. Tavridou, "Pharmacogenomics of oral antidiabetic medications: current data and pharmacoepigenomic perspective," Pharmacogenomics, vol. 12, no. 8, pp. 1161-1191, 2011.

[7] C. Huang and J. C. Florez, "Pharmacogenetics in type 2 diabetes: potential implications for clinical practice," Genome Medicine, vol. 3, no. 11, article 76, 2011.

[8] D. Altshuler, J. N. Hirschhorn, M. Klannemark et al., "The common PPAR $\gamma$ Prol2Ala polymorphism is associated with decreased risk of type 2 diabetes," Nature Genetics, vol. 26, no. 1, pp. 76-80, 2000.

[9] A. L. Gloyn, M. N. Weedon, K. R. Owen et al., "Large-scale association studies of variants in genes encoding the pancreatic $\beta$ cell $\mathrm{K}_{A T P}$ channel subunits Kir6.2 (KCNJ11) and SUR1 (ABCC8) confirm that the KCNJ11 E23K variant is associated with type 2 diabetes," Diabetes, vol. 52, no. 2, pp. 568-572, 2003.

[10] S. F. A. Grant, G. Thorleifsson, I. Reynisdottir et al., "Variant of transcription factor 7-like 2 (TCF7L2) gene confers risk of type 2 diabetes," Nature Genetics, vol. 38, no. 3, pp. 320-323, 2006.
[11] M. S. Sandhu, M. N. Weedon, K. A. Fawcett et al., "Common variants in WFS1 confer risk of type 2 diabetes," Nature Genetics, vol. 39, no. 8, pp. 951-953, 2007.

[12] J. Gudmundsson, P. Sulem, V. Steinthorsdottir et al., "Two variants on chromosome 17 confer prostate cancer risk, and the one in TCF2 protects against type 2 diabetes," Nature Genetics, vol. 39, no. 8, pp. 977-983, 2007.

[13] E. Zeggini, M. N. Weedon, C. M. Lindgren et al., "Replication of genome-wide association signals in UK samples reveals risk loci for type 2 diabetes," Science, vol. 316, no. 5829, pp. 1336-1341, 2007.

[14] R. Saxena, B. F. Voight, V. Lyssenko et al., "Genome-wide association analysis identifies loci for type 2 diabetes and triglyceride levels," Science, vol. 316, no. 5829, pp. 1331-1336, 2007.

[15] L. J. Scott, K. L. Mohlke, L. L. Bonnycastle et al., "A genome-wide association study of type 2 diabetes in Finns detects multiple susceptibility variants," Science, vol. 316, no. 5829, pp. 1341-1345, 2007.

[16] V. Steinthorsdottir, G. Thorleifsson, I. Reynisdottir et al., "A variant in CDKAL1 influences insulin response and risk of type 2 diabetes," Nature Genetics, vol. 39, no. 6, pp. 770-775, 2007.

[17] R. Sladek, G. Rocheleau, J. Rung et al., "A genome-wide association study identifies novel risk loci for type 2 diabetes," Nature, vol. 445, no. 7130, pp. 881-885, 2007.

[18] P. R. Burton, D. G. Clayton, L. R. Cardon et al., "Genome-wide association study of 14,000 cases of seven common diseases and 3,000 shared controls," Nature, vol. 447, no. 7145, pp. 661-678, 2007.

[19] E. Zeggini, L. J. Scott, R. Saxena, and B. F. Voight, "Meta-analysis of genome-wide association data and large-scale replication identifies additional susceptibility loci for type 2 diabetes," Nature Genetics, vol. 40, no. 5, pp. 638-645, 2008.

[20] N. Bouatia-Naji, A. Bonnefond, C. Cavalcanti-Proença et al., "A variant near MTNR1B is associated with increased fasting plasma glucose levels and type 2 diabetes risk," Nature Genetics, vol. 41, no. 1, pp. 89-94, 2009.

[21] J. Rung, S. Cauchi, A. Albrechtsen et al., "Genetic variant near IRS1 is associated with type 2 diabetes, insulin resistance and hyperinsulinemia," Nature Genetics, vol. 41, no. 10, pp. 1110-1115, 2009.

[22] J. Dupuis, C. Langenberg, I. Prokopenko et al., "New genetic loci implicated in fasting glucose homeostasis and their impact on type 2 diabetes risk," Nature Genetics, vol. 42, no. 2, pp. 105-116, 2010.

[23] L. Qi, M. C. Cornelis, P. Kraft et al., "Genetic variants at 2q24 are associated with susceptibility to type 2 diabetes," Human Molecular Genetics, vol. 19, no. 13, pp. 2706-2715, 2010.

[24] B. F. Voight, L. J. Scott, V. Steinthorsdottir et al., "Twelve type 2 diabetes susceptibility loci identified through large-scale association analysis," Nature Genetics, vol. 42, no. 7, pp. 579-589, 2010.

[25] A. P. Morris, B. F. Voight, T. M. Teslovich et al., "Largescale association analysis provides insights into the genetic architecture and pathophysiology of type 2 diabetes," Nature Genetics, vol. 44, no. 9, pp. 981-990, 2012.

[26] C. Hu, C. Wang, R. Zhang et al., "Variations in KCNQ1 are associated with type 2 diabetes and beta cell function in a Chinese population," Diabetologia, vol. 52, no. 7, pp. 1322-1325, 2009. 
[27] T. Yamauchi, K. Hara, S. Maeda et al., "A genome-wide association study in the Japanese population identifies susceptibility loci for type 2 diabetes at UBE2E2 and C2CD4A-C2CD4B," Nature Genetics, vol. 42, no. 10, pp. 864-868, 2010.

[28] X. O. Shu, J. Long, Q. Cai et al., "Identification of new genetic risk variants for type 2 diabetes," PLoS Genetics, vol. 6, no. 9, Article ID e1001127, 2010.

[29] F.-J. Tsai, C.-F. Yang, C.-C. Chen et al., "A genome-wide association study identifies susceptibility variants for type 2 diabetes in Han Chinese," PLoS Genetics, vol. 6, no. 2, Article ID e1000847, 2010.

[30] Y. S. Cho, C. H. Chen, C. Hu et al., "Meta-analysis of genomewide association studies identifies eight new loci for type 2 diabetes in east Asians," Nature Genetics, vol. 44, no. 1, pp. 67-72, 2012.

[31] M. Imamura, S. Maeda, T. Yamauchi et al., "A single-nucleotide polymorphism in $A N K 1$ is associated with susceptibility to type 2 diabetes in Japanese populations," Human Molecular Genetics, vol. 21, no. 13, pp. 3042-3049, 2012.

[32] H. Li, W. Gan, L. Lu et al., "A genome-wide association study identifies GRK5 and RASGRP1 as type 2 diabetes loci in Chinese Hans," Diabetes, vol. 62, no. 1, pp. 291-298, 2013.

[33] R. C. Ma, C. Hu, C. H. Tam et al., "Genome-wide association study in a Chinese population identifies a susceptibility locus for type 2 diabetes at 7q32 near PAX4," Diabetologia, vol. 56, no. 6, pp. 1291-1305, 2013.

[34] K. Hara, H. Fujita, T. A. Johnson et al., "Genome-wide association study identifies three novel loci for type 2 diabetes," Human Molecular Genetics, vol. 23, no. 1, pp. 239-246, 2014.

[35] J. S. Kooner, D. Saleheen, X. Sim et al., "Genome-wide association study in individuals of South Asian ancestry identifies six new type 2 diabetes susceptibility loci," Nature Genetics, vol. 43, no. 10, pp. 984-989, 2011.

[36] R. Tabassum, G. Chauhan, O. P. Dwivedi et al., "Genome-wide association study for type 2 diabetes in Indians identifies a new susceptibility locus at 2q21," Diabetes, vol. 62, no. 3, pp. 977-986, 2013.

[37] R. Saxena, D. Saleheen, L. F. Been et al., "Genome-wide association study identifies a novel locus contributing to type 2 diabetes susceptibility in Sikhs of Punjabi origin from India," Diabetes, vol. 62, no. 5, pp. 1746-1755, 2013.

[38] S. S. Fajans, G. I. Bell, and K. S. Polonsky, "Molecular mechanisms and clinical pathophysiology of maturity-onset diabetes of the young," The New England Journal of Medicine, vol. 345, no. 13, pp. 971-980, 2001.

[39] I. Barroso, "Genetics of type 2 diabetes," Diabetic Medicine, vol. 22 , no. 5, pp. 517-535, 2005.

[40] M. Vaxillaire and P. Froguel, "Monogenic diabetes in the young, pharmacogenetics and relevance to multifactorial forms of type 2 diabetes," Endocrine Reviews, vol. 29, no. 3, pp. 254-264, 2008.

[41] Y. Horikawa, N. Oda, N. J. Cox et al., "Genetic variation in the gene encoding calpain-10 is associated with type 2 diabetes mellitus," Nature Genetics, vol. 26, no. 2, pp. 163-175, 2000.

[42] D. Meyre, N. Bouatia-Naji, A. Tounian et al., "Variants of ENPP1 are associated with childhood and adult obesity and increase the risk of glucose intolerance and type 2 diabetes," Nature Genetics, vol. 37, no. 8, pp. 863-867, 2005.

[43] L. D. Love-Gregory, J. Wasson, J. Ma et al., "A common polymorphism in the upstream promoter region of the hepatocyte nuclear factor- $4 \alpha$ gene on chromosome $20 \mathrm{q}$ is associated with type 2 diabetes and appears to contribute to the evidence for linkage in an Ashkenazi Jewish population," Diabetes, vol. 53, no. 4, pp. 1134-1140, 2004.

[44] K. Silander, K. L. Mohlke, L. J. Scott et al., "Genetic variation near the hepatocyte nuclear factor- $4 \alpha$ gene predicts susceptibility to type 2 diabetes," Diabetes, vol. 53, no. 4, pp. 1141-1149, 2004.

[45] F. Vasseur, N. Helbecque, C. Dina et al., "Single-nucleotide polymorphism haplotypes in the both proximal promoter and exon 3 of the APM1 gene modulate adipocyte-secreted adiponectin hormone levels and contribute to the genetic risk for type 2 diabetes in French Caucasians," Human Molecular Genetics, vol. 11, no. 21, pp. 2607-2614, 2002.

[46] S. S. Deeb, L. Fajas, M. Nemoto et al., "A Pro12Ala substitution in PPAR $\gamma 2$ associated with decreased receptor activity, lower body mass index and improved insulin sensitivity;" Nature Genetics, vol. 20, no. 3, pp. 284-287, 1998.

[47] A. Karasik, C. O’Hara, S. Srikanta et al., "Genetically programmed selective islet $\beta$-cell loss in diabetic subjects with Wolfram's syndrome," Diabetes Care, vol. 12, no. 2, pp. 135-138, 1989.

[48] A. C. Riggs, E. Bernal-Mizrachi, M. Ohsugi et al., "Mice conditionally lacking the Wolfram gene in pancreatic islet beta cells exhibit diabetes as a result of enhanced endoplasmic reticulum stress and apoptosis," Diabetologia, vol. 48, no. 11, pp. 2313-2321, 2005.

[49] T. Yamada, H. Ishihara, A. Tamura et al., "WFS1-deficiency increases endoplasmic reticulum stress, impairs cell cycle progression and triggers the apoptotic pathway specifically in pancreatic $\beta$-cells," Human Molecular Genetics, vol. 15, no. 10, pp. 1600-1609, 2006.

[50] C. J. Groves, E. Zeggini, J. Minton et al., "Association analysis of 6,736 UK subjects provides replication and confirms TCF7L2 as a type 2 diabetes susceptibility gene with a substantial effect on individual risk," Diabetes, vol. 55, no. 9, pp. 2640-2644, 2006.

[51] C. Zhang, L. Qi, D. J. Hunter et al., "Variant of transcription factor 7-like 2 (TCF7L2) gene and the risk of type 2 diabetes in large cohorts of US women and men," Diabetes, vol. 55, no. 9, pp. 2645-2648, 2006.

[52] L. J. Scott, L. L. Bonnycastle, C. J. Willer et al., "Association of transcription factor 7-like 2 (TCF7L2) variants with type 2 diabetes in a Finnish sample," Diabetes, vol. 55, no. 9, pp. 26492653, 2006.

[53] C. M. Damcott, T. I. Pollin, L. J. Reinhart et al., "Polymorphisms in the transcription factor 7-like 2 (TCF7L2) gene are associated with type 2 diabetes in the Amish: replication and evidence for a role in both insulin secretion and insulin resistance," Diabetes, vol. 55, no. 9, pp. 2654-2659, 2006.

[54] R. Saxena, L. Gianniny, N. P. Burtt et al., "Common single nucleotide polymorphisms in TCF7L2 are reproducibly associated with type 2 diabetes and reduce the insulin response to glucose in nondiabetic individuals," Diabetes, vol. 55, no. 10, pp. 2890-2895, 2006.

[55] S. Cauchi, D. Meyre, C. Dina et al., "Transcription factor TCF7L2 genetic study in the French population: expression in human $\beta$-cells and adipose tissue and strong association with type 2 diabetes," Diabetes, vol. 55, no. 10, pp. 2903-2908, 2006.

[56] T. Hayashi, Y. Iwamoto, K. Kaku, H. Hirose, and S. Maeda, "Replication study for the association of TCF7L2 with susceptibility to type 2 diabetes in a Japanese population," Diabetologia, vol. 50, no. 5, pp. 980-984, 2007.

[57] M. Horikoshi, K. Hara, C. Ito, R. Nagai, P. Froguel, and T. Kadowaki, "A genetic variation of the transcription factor 7-like 
2 gene is associated with risk of type 2 diabetes in the Japanese population," Diabetologia, vol. 50, no. 4, pp. 747-751, 2007.

[58] A. C. Foley and M. Mercola, "Heart induction by Wnt antagonists depends on the homeodomain transcription factor Hex," Genes \& Development, vol. 19, no. 3, pp. 387-396, 2005.

[59] A. M. Simonis-Bik, G. Nijpels, T. W. van Haeften et al., "Gene variants in the novel type 2 diabetes loci CDC123/CAMK1D, THADA, ADAMTS9, BCL11A, and MTNR1B affect different aspects of pancreatic $\beta$-cell function," Diabetes, vol. 59, no. 1 , pp. 293-301, 2010.

[60] N. Grarup, G. Andersen, N. T. Krarup et al., "Association testing of novel type 2 diabetes risk alleles in the JAZF1, CDC123/CAMK1D, TSPAN8, THADA, ADAMTS9, and NOTCH2 Loci with insulin release, insulin sensitivity, and obesity in a population-based sample of 4,516 glucose-tolerant middle-aged danes," Diabetes, vol. 57, no. 9, pp. 2534-2540, 2008.

[61] I. Prokopenko, C. Langenberg, J. C. Florez et al., "Variants in MTNR1B influence fasting glucose levels," Nature Genetics, vol. 41, no. 1, pp. 77-81, 2009.

[62] J. S. Willson, T. D. Godwin, G. A. Wiggins et al., "Primary hepatocellular neoplasms in a $\mathrm{MODY}_{3}$ family with a novel HNF1A germline mutation," Journal of Hepatology, vol. 59, no. 4, pp. 904-907, 2013.

[63] D. M. Lim, N. Huh, and K. Y. Park, "Hepatocyte nuclear factor 1$\alpha$ mutation in normal glucose-tolerant subjects and early-onset type 2 diabetic patients," Korean Journal of Internal Medicine, vol. 23, no. 4, pp. 165-169, 2008.

[64] R. A. Hegele, H. Cao, S. B. Harris, A. J. G. Hanley, and B. Zinman, "The hepatic nuclear factor- $1 \alpha$ G319S variant is associated with early-onset type 2 diabetes in Canadian OjiCree," The Journal of Clinical Endocrinology \& Metabolism, vol. 84, no. 3, pp. 1077-1082, 1999.

[65] H. Xu, M. Dembski, Q. Yang et al., "Dual specificity mitogenactivated protein (MAP) kinase phosphatase-4 plays a potential role in insulin resistance," The Journal of Biological Chemistry, vol. 278, no. 32, pp. 30187-30192, 2003.

[66] M. Bazuine, F. Carlotti, R. S. Tafrechi, R. C. Hoeben, and J. A. Maassen, "Mitogen-activated protein kinase (MAPK) phosphatase-1 and -4 attenuate p38 MAPK during dexamethasone-induced insulin resistance in 3T3L1 adipocytes," Molecular Endocrinology, vol. 18, no. 7, pp. 1697-1707, 2004.

[67] B. Emanuelli, D. Eberlé, R. Suzuki, and C. R. Kahn, "Overexpression of the dual-specificity phosphatase MKP-4/DUSP-9 protects against stress-induced insulin resistance," Proceedings of the National Academy of Sciences of the United States of America, vol. 105, no. 9, pp. 3545-3550, 2008.

[68] M. N. Harder, R. Ribel-Madsen, J. M. Justesen et al., "Type 2 diabetes risk alleles near BCAR1 and in ANK1 associate with decreased $\beta$-cell function whereas risk alleles near ANKRD55 and GRB14 associate with decreased insulin sensitivity in the Danish Inter99 cohort," The Journal of Clinical Endocrinology \& Metabolism, vol. 98, no. 4, pp. E801-E806, 2013.

[69] H. Li, B. Oldenburg, C. Chamberlain et al., "Diabetes prevalence and determinants in adults in China mainland from 2000 to 2010: a systematic review," Diabetes Research and Clinical Practice, vol. 98, no. 2, pp. 226-235, 2012.

[70] K. Yasuda, K. Miyake, Y. Horikawa et al., "Variants in KCNQ1 are associated with susceptibility to type 2 diabetes mellitus," Nature Genetics, vol. 40, no. 9, pp. 1092-1097, 2008.
[71] H. Unoki, A. Takahashi, T. Kawaguchi et al., "SNPs in KCNQ1 are associated with susceptibility to type 2 diabetes in East Asian and European populations," Nature Genetics, vol. 40, no. 9, pp. 1098-1102, 2008.

[72] Y.-H. Lee, E. S. Kang, S. H. Kim et al., "Association between polymorphisms in SLC30A8, HHEX, CDKN2A/B, IGF2BP2, FTO, WFS1, CDKAL1, KCNQ1 and type 2 diabetes in the Korean population," Journal of Human Genetics, vol. 53, no. 11-12, pp. 991-998, 2008.

[73] J. T. Tan, S. Nurbaya, D. Gardner, S. Ye, E. S. Tai, and D. P. K. $\mathrm{Ng}$, "Genetic variation in KCNQ1 associates with fasting glucose and $\beta$-cell function: a study of 3,734 subjects comprising three ethnicities living in Singapore," Diabetes, vol. 58, no. 6, pp. 14451449, 2009.

[74] K. Müssig, H. Staiger, F. Machicao et al., "Association of type 2 diabetes candidate polymorphisms in KCNQ1 with incretin and insulin secretion," Diabetes, vol. 58, no. 7, pp. 1715-1720, 2009.

[75] Y. C. Chang, Y. F. Chiu, P. H. Liu et al., "Replication of genomewide association signals of type 2 diabetes in Han Chinese in a prospective cohort," Clinical Endocrinology, vol. 76, no. 3, pp. 365-372, 2012.

[76] H. Wolosker, S. Blackshaw, and S. H. Snyder, "Serine racemase: a glial enzyme synthesizing D-serine to regulate glutamate$\mathrm{N}$-methyl-D-aspartate neurotransmission," Proceedings of the National Academy of Sciences of the United States of America, vol. 96, no. 23, pp. 13409-13414, 1999.

[77] H. Wolosker, K. N. Sheth, M. Takahashi et al., "Purification of serine racemase: biosynthesis of the neuromodulator D-serine," Proceedings of the National Academy of Sciences of the United States of America, vol. 96, no. 2, pp. 721-725, 1999.

[78] N. Soranzo, S. Sanna, E. Wheeler et al., "Common variants at 10 genomic loci influence hemoglobin $\mathrm{A}_{1 C}$ levels via glycemic and nonglycemic pathways," Diabetes, vol. 59, no. 12, pp. 3229-3239, 2010.

[79] L. Wang, M. Shen, F. Wang et al., "GRK5 ablation contributes to insulin resistance," Biochemical and Biophysical Research Communications, vol. 429, no. 1-2, pp. 99-104, 2012.

[80] J. Wang, L. Elghazi, S. E. Parker et al., "The concerted activities of PAX 4 and Nkx2.2 are essential to initiate pancreatic $\beta$-cell differentiation," Developmental Biology, vol. 266, no. 1, pp. 178189, 2004.

[81] Y. Zhang, R. Proenca, M. Maffei, M. Barone, L. Leopold, and J. M. Friedman, "Positional cloning of the mouse obese gene and its human homologue," Nature, vol. 372, no. 6505, pp. 425-432, 1994.

[82] Y. Liu, L. Yu, D. Zhang et al., "Positive association between variations in CDKAL1 and type 2 diabetes in Han Chinese individuals," Diabetologia, vol. 51, no. 11, pp. 2134-2137, 2008.

[83] M. Xu, Y. Bi, Y. Xu et al., "Combined effects of 19 common variations on type 2 diabetes in Chinese: results from two community-based studies," PLoS ONE, vol. 5, no. 11, Article ID e14022, 2010.

[84] Y. Wu, H. Li, R. J. F. Loos et al., "Common variants in CDKAL1, CDKN2A/B, IGF2BP2, SLC30A8, and HHEX/IDE genes are associated with type 2 diabetes and impaired fasting glucose in a Chinese Han population," Diabetes, vol. 57 , no. 10, pp. $2834-$ 2842, 2008.

[85] Y. Liu, Z. Liu, Y. Song et al., "Meta-analysis added power to identify variants in FTO associated with type 2 diabetes and obesity in the Asian population," Obesity, vol. 18, no. 8, pp. 1619$1624,2010$. 
[86] J. Wen, T. Rönn, A. Olsson et al., "Investigation of type 2 diabetes risk alleles support CDKN2A/B, CDKAL1, and TCF7L2 as susceptibility genes in a Han Chinese cohort," PLoS ONE, vol. 5, no. 2, Article ID e9153, 2010.

[87] C. Hu, R. Zhang, C. Wang et al., "PPARG, KCNJ11, CDKAL1, CDKN2A-CDKN2B, IDE-KIF11-HHEX, IGF2BP2 and SLC30A8 are associated with type 2 diabetes in a chinese population," PLoS ONE, vol. 4, no. 10, Article ID e7643, 2009.

[88] J. Xiang, X.-Y. Li, M. Xu et al., "Zinc transporter-8 gene (SLC30A8) is associated with type 2 diabetes in Chinese," The Journal of Clinical Endocrinology \& Metabolism, vol. 93, no. 10, pp. 4107-4112, 2008.

[89] T. Rönn, J. Wen, Z. Yang et al., "A common variant in MTNR1B, encoding melatonin receptor $1 \mathrm{~B}$, is associated with type 2 diabetes and fasting plasma glucose in Han Chinese individuals," Diabetologia, vol. 52, no. 5, pp. 830-833, 2009.

[90] M. C. Y. Ng, C. H. T. Tam, V. K. L. Lam, W.-Y. So, R. C. W. Ma, and J. C. N. Chan, "Replication and identification of novel variants at TCF7L2 associated with type 2 diabetes in Hong Kong Chinese," The Journal of Clinical Endocrinology \& Metabolism, vol. 92, no. 9, pp. 3733-3737, 2007.

[91] M. C. Y. Ng, K. S. Park, B. Oh et al., "Implication of genetic variants near TCF7L2, SLC30A8, HHEX, CDKAL1, CDKN2A/B, IGF2BP2, and FTO in type 2 diabetes and obesity in 6,719 Asians," Diabetes, vol. 57, no. 8, pp. 2226-2233, 2008.

[92] Y.-C. Chang, T.-J. Chang, Y.-D. Jiang et al., "Association study of the genetic polymorphisms of the transcription factor 7-like 2 (TCF7L2) gene and type 2 diabetes in the Chinese population," Diabetes, vol. 56, no. 10, pp. 2631-2637, 2007.

[93] H. Fukuda, M. Imamura, Y. Tanaka et al., "A single nucleotide polymorphism within DUSP9 is associated with susceptibility to type 2 diabetes in a Japanese population," PLoS One, vol. 7, no. 9, Article ID e46263, 2012.

[94] B. Basnyat and L. C. Rajapaksa, "Cardiovascular and infectious diseases in South Asia: the double whammy," British Medical Journal, vol. 328, no. 7443, p. 781, 2004.

[95] R. M. Anjana, R. Pradeepa, M. Deepa et al., "Prevalence of diabetes and prediabetes (impaired fasting glucose and/or impaired glucose tolerance) in urban and rural India: phase i results of the Indian Council of Medical Research-INdia DIABetes (ICMR-INDIAB) study," Diabetologia, vol. 54, no. 12, pp. 3022-3027, 2011.

[96] A. Ramachandran, R. C. Ma, and C. Snehalatha, "Diabetes in Asia," The Lancet, vol. 375, no. 9712, pp. 408-418, 2010.

[97] J. C. Chambers, O. A. Obeid, H. Refsum et al., "Plasma homocysteine concentrations and risk of coronary heart disease in UK Indian Asian and European men," The Lancet, vol. 355, no. 9203, pp. 523-527, 2000.

[98] D. K. Sanghera, L. Ortega, S. Han et al., "Impact of nine common type 2 diabetes risk polymorphisms in Asian Indian Sikhs: PPARG2 (Pro12Ala), IGF2BP2, TCF7L2 and FTO variants confer a significant risk," BMC Medical Genetics, vol. 9, article 59, 2008.

[99] C. S. Yajnik, C. S. Janipalli, S. Bhaskar et al., "FTO gene variants are strongly associated with type 2 diabetes in South Asian Indians," Diabetologia, vol. 52, no. 2, pp. 247-252, 2009.

[100] M. Chidambaram, V. Radha, and V. Mohan, "Replication of recently described type 2 diabetes gene variants in a South Indian population," Metabolism, vol. 59, no. 12, pp. 1760-1766, 2010.

[101] G. Chauhan, C. J. Spurgeon, R. Tabassum et al., "Impact of common variants of PPARG, KCNJ11, TCF7L2, SLC30A8,
HHEX, CDKN2A, IGF2BP2, and CDKAL1 on the risk of type 2 diabetes in 5,164 Indians," Diabetes, vol. 59, no. 8, pp. 20682074, 2010.

[102] S. D. Rees, M. Z. I. Hydrie, A. S. Shera et al., "Replication of 13 genome-wide association (GWA)-validated risk variants for type 2 diabetes in Pakistani populations," Diabetologia, vol. 54, no. 6, pp. 1368-1374, 2011.

[103] L. Ma, R. L. Hanson, L. N. Que et al., "Variants in ARHGEF11, a candidate gene for the linkage to type 2 diabetes on chromosome 1q, are nominally associated with insulin resistance and type 2 diabetes in Pima Indians," Diabetes, vol. 56, no. 5, pp. 1454-1459, 2007.

[104] L. Ma, R. L. Hanson, L. N. Que et al., "PCLO variants are nominally associated with early-onset type 2 diabetes and insulin resistance in Pima Indians," Diabetes, vol. 57, no. 11, pp. 3156-3160, 2008.

[105] L. Bian, R. L. Hanson, Y. L. Muller et al., "Variants in ACAD10 are associated with type 2 diabetes, insulin resistance and lipid oxidation in Pima Indians," Diabetologia, vol. 53, no. 7, pp. 13491353, 2010.

[106] L. Bian, R. L. Hanson, V. Ossowski et al., "Variants in ASK1 are associated with skeletal muscle $A S K 1$ expression, in vivo insulin resistance, and type 2 diabetes in Pima Indians," Diabetes, vol. 59, no. 5, pp. 1276-1282, 2010.

[107] R. Rong, R. L. Hanson, D. Ortiz et al., "Association analysis of variation in/near FTO, CDKAL1, SLC30A8, HHEX, EXT2, IGF2BP2, LOC387761, and CDKN2B with type 2 diabetes and related quantitative traits in Pima Indians," Diabetes, vol. 58, no. 2, pp. 478-488, 2009.

[108] M. G. Hayes, A. Pluzhnikov, K. Miyake et al., "Identification of type 2 diabetes genes in Mexican Americans through genomewide association studies," Diabetes, vol. 56 , no. 12 , pp. $3033-$ 3044, 2007.

[109] J. E. Below, E. R. Gamazon, J. V. Morrison et al., "Genomewide association and meta-analysis in populations from Starr County, Texas, and Mexico City identify type 2 diabetes susceptibility loci and enrichment for expression quantitative trait loci in top signals," Diabetologia, vol. 54, no. 8, pp. 2047-2055, 2011.

[110] "Sequence variants in SLC16A11 are a common risk factor for type 2 diabetes in Mexico," Nature, vol. 506, pp. 97-101, 2013.

[111] V. Lyssenko, C. L. F. Nagorny, M. R. Erdos et al., "Common variant in MTNR1B associated with increased risk of type 2 diabetes and impaired early insulin secretion," Nature Genetics, vol. 41, no. 1, pp. 82-88, 2009.

[112] T. W. Boesgaard, N. Grarup, T. Jørgensen, K. Borch-Johnsen, T. Hansen, and O. Pedersen, "Variants at DGKB/TMEM195, $A D R A 2 A, G L I S 3$ and $C 2 C D 4 B$ loci are associated with reduced glucose-stimulated beta cell function in middle-aged Danish people," Diabetologia, vol. 53, no. 8, pp. 1647-1655, 2010.

[113] T. Nielsen, T. Sparsø, N. Grarup et al., "Type 2 diabetes risk allele near CENTD2 is associated with decreased glucose-stimulated insulin release," Diabetologia, vol. 54, no. 5, pp. 1052-1056, 2011.

[114] S. D. Rees, M. Z. I. Hydrie, J. P. O’Hare et al., "Effects of 16 genetic variants on fasting glucose and type 2 diabetes in South Asians: ADCY5 and GLIS3 variants may predispose to type 2 diabetes," PLoS ONE, vol. 6, no. 9, Article ID e24710, 2011.

[115] T. W. Boesgaard, A. P. Gjesing, N. Grarup et al., "Variant near ADAMTS9 known to associate with type 2 diabetes is related to insulin resistance in offspring of type 2 diabetes patientsEUGENE2 study," PLoS ONE, vol. 4, no. 9, Article ID e7236, 2009. 
[116] A. Anand and K. Chada, "In vivo modulation of Hmgic reduces obesity," Nature Genetics, vol. 24, no. 4, pp. 377-380, 2000.

[117] T. Q. Binh, P. T. Phuong, B. T. Nhung et al., "Association of the common FTO-rs9939609 polymorphism with type 2 diabetes, independent of obesity-related traits in a Vietnamese population," Gene, vol. 513, no. 1, pp. 31-35, 2013.

[118] B. Xi, F. Takeuchi, G. R. Chandak et al., "Common polymorphism near the $M C 4 R$ gene is associated with type 2 diabetes: data from a meta-analysis of 123, 373 individuals," Diabetologia, vol. 55, no. 10, pp. 2660-2666, 2012.

[119] V. Lyssenko, R. Lupi, P. Marchetti et al., "Mechanisms by which common variants in the TCF7L2 gene increase risk of type 2 diabetes," The Journal of Clinical Investigation, vol. 117, no. 8, pp. 2155-2163, 2007.

[120] D. T. Villareal, H. Robertson, G. I. Bell et al., "TCF7L2 variant rs7903146 affects the risk of type 2 diabetes by modulating incretin action," Diabetes, vol. 59, no. 2, pp. 479-485, 2010.

[121] O. le Bacquer, J. Kerr-Conte, S. Gargani et al., "TCF7L2 rs7903146 impairs islet function and morphology in nondiabetic individuals," Diabetologia, vol. 55, no. 10, pp. 2677-2681, 2012.

[122] Y. Takeda, Y. Fujita, J. Honjo et al., "Reduction of both $\beta$ cell death and alpha cell proliferation by dipeptidyl peptidase- 4 inhibition in a streptozotocin-induced model of diabetes in mice," Diabetologia, vol. 55, no. 2, pp. 404-412, 2012.

[123] K. H. Yoon, S. H. Ko, J. H. Cho et al., "Selective $\beta$-cell loss and $\alpha$-cell expansion in patients with type 2 diabetes mellitus in Korea," The Journal of Clinical Endocrinology \& Metabolism, vol. 88, no. 5, pp. 2300-2308, 2003.

[124] C. L. Kirkpatrick, P. Marchetti, F. Purrello et al., "Type 2 diabetes susceptibility gene expression in normal or diabetic sorted human alpha and beta cells: correlations with age or BMI of islet donors," PLoS ONE, vol. 5, no. 6, Article ID el1053, 2010.

[125] V. Korinek, N. Barker, P. Moerer et al., "Depletion of epithelial stem-cell compartments in the small intestine of mice lacking Tcf-4," Nature Genetics, vol. 19, no. 4, pp. 379-383, 1998.

[126] W. Ip, Y. T. Chiang, and T. Jin, “The involvement of the Wnt signaling pathway and TCF7L2 in diabetes mellitus: the current understanding, dispute, and perspective," Cell \& Bioscience, vol. 2, no. 1, article 28, 2012.

[127] J. Dessimoz, C. Bonnard, J. Huelsken, and A. Grapin-Botton, "Pancreas-specific deletion of $\beta$-catenin reveals Wnt-dependent and Wnt-independent functions during development," Current Biology, vol. 15, no. 18, pp. 1677-1683, 2005.

[128] L. C. Murtaugh, A. C. Law, Y. Dor, and D. A. Melton, " $\beta$-catenin is essential for pancreatic acinar but not islet development," Development, vol. 132, no. 21, pp. 4663-4674, 2005.

[129] S. Papadopoulou and H. Edlund, "Attenuated Wnt signaling perturbs pancreatic growth but not pancreatic function," Diabetes, vol. 54, no. 10, pp. 2844-2851, 2005.

[130] P. W. Heiser, J. Lau, M. M. Taketo, P. L. Herrera, and M. Hebrok, "Stabilization of $\beta$-catenin impacts pancreas growth," Development, vol. 133, no. 10, pp. 2023-2032, 2006.

[131] R. S. Heller, D. S. Dichmann, J. Jensen et al., "Expression patterns of Wnts, Frizzleds, sFRPs, and misexpression in transgenic mice suggesting a role for Wnts in pancreas and foregut pattern formation," Developmental Dynamics, vol. 225, no. 3, pp. 260$270,2002$.

[132] I. C. Rulifson, S. K. Karnik, P. W. Heiser et al., "Wnt signaling regulates pancreatic $\beta$ cell proliferation," Proceedings of the National Academy of Sciences of the United States of America, vol. 104, no. 15, pp. 6247-6252, 2007.
[133] S. F. Boj, J. H. van Es, M. Huch et al., "Diabetes risk gene and Wnt effector TCF7L2/TCF4 controls hepatic response to perinatal and adult metabolic demand," Cell, vol. 151, no. 7, pp. 1595-1607, 2012.

[134] F. Chimienti, A. Favier, and M. Seve, "ZnT-8, a pancreatic $\beta$-cellspecific zinc transporter," Biometals, vol. 18, no. 4, pp. 313-317, 2005.

[135] M. Tamaki, Y. Fujitani, T. Uchida, T. Hirose, R. Kawamori, and $\mathrm{H}$. Watada, "Downregulation of ZnT8 expression in pancreatic $\beta$-cells of diabetic mice," Islets, vol. 1, no. 2, pp. 124-128, 2009.

[136] L. D. Pound, S. A. Sarkar, R. K. P. Benninger et al., "Deletion of the mouse Slc30a8 gene encoding zinc transporter-8 results in impaired insulin secretion," Biochemical Journal, vol. 421, no. 3, pp. 371-376, 2009.

[137] M. Tamaki, Y. Fujitani, A. Hara et al., "The diabetes-susceptible gene SLC30A8/ZnT8 regulates hepatic insulin clearance," The Journal of Clinical Investigation, vol. 123, no. 10, pp. 4513-4524, 2013.

[138] F. Chimienti, S. Devergnas, F. Pattou et al., "In vivo expression and functional characterization of the zinc transporter ZnT8 in glucose-induced insulin secretion," Journal of Cell Science, vol. 119, no. 20, pp. 4199-4206, 2006.

[139] L. D. Pound, Y. Hang, S. A. Sarkar et al., "The pancreatic islet $\beta$-cell-enriched transcription factor Pdx-1 regulates Slc30a8 gene transcription through an intronic enhancer," Biochemical Journal, vol. 433, no. 1, pp. 95-105, 2011.

[140] Q. Qi and F. B. Hu, "Genetics of type 2 diabetes in European populations," Journal of Diabetes, vol. 4, no. 3, pp. 203-212, 2012.

[141] M. Imamura, D. Shigemizu, T. Tsunoda et al., "Assessing the clinical utility of a genetic risk score constructed using 49 susceptibility alleles for type 2 diabetes in a Japanese population," The Journal of Clinical Endocrinology \& Metabolism, vol. 98, no. 10, pp. 1667-1673, 2013.

[142] J. N. Cooke, M. C. Y. Ng, N. D. Palmer et al., "Genetic risk assessment of type 2 diabetes-associated polymorphisms in African Americans," Diabetes Care, vol. 35, no. 2, pp. 287-292, 2012.

[143] M. Iwata, S. Maeda, Y. Kamura et al., "Genetic risk score constructed using 14 susceptibility alleles for type 2 diabetes is associated with the early onset of diabetes and may predict the future requirement of insulin injections among Japanese individuals," Diabetes Care, vol. 35, no. 8, pp. 1763-1770, 2012.

[144] P. J. Talmud, A. D. Hingorani, J. A. Cooper et al., "Utility of genetic and non-genetic risk factors in prediction of type 2 diabetes: Whitehall II prospective cohort study," British Medical Journal, vol. 340, Article ID b4838, 2010.

[145] J. M. de Miguel-Yanes, P. Shrader, M. J. Pencina et al., "Genetic risk reclassification for type 2 diabetes by age below or above 50 years using 40 type 2 diabetes risk single nucleotide polymorphisms," Diabetes Care, vol. 34, no. 1, pp. 121-125, 2011.

[146] M. C. Cornelis and F. B. Hu, "Gene-environment interactions in the development of type 2 diabetes: recent progress and continuing challenges," Annual Review of Nutrition, vol. 32, pp. 245-259, 2012.

[147] L. Wang, H. L. McLeod, and R. M. Weinshilboum, "Genomics and drug response," The New England Journal of Medicine, vol. 364, no. 12, pp. 1144-1153, 2011.

[148] G. C. Mannino and G. Sesti, "Individualized therapy for type 2 diabetes: clinical implications of pharmacogenetic data," Molecular Diagnosis \& Therapy, vol. 16, no. 5, pp. 285-302, 2012. 
[149] H. Xu, M. Murray, and A. J. McLachlan, "Influence of genetic polymorphisms on the pharmacokinetics and pharmacodynamics of sulfonylurea drugs," Current Drug Metabolism, vol. 10, no. 6, pp. 643-658, 2009.

[150] A. Surendiran, S. C. Pradhan, A. Agrawal et al., "Influence of CYP2C9 gene polymorphisms on response to glibenclamide in type 2 diabetes mellitus patients," European Journal of Clinical Pharmacology, vol. 67, no. 8, pp. 797-801, 2011.

[151] M. Rafiq, S. E. Flanagan, A.-M. Patch et al., "Effective treatment with oral sulfonylureas in patients with diabetes due to sulfonylurea receptor 1 (SUR1) mutations," Diabetes Care, vol. 31, no. 2, pp. 204-209, 2008.

[152] Y. Feng, G. Mao, X. Ren et al., "Ser1369Ala variant in sulfonylurea receptor gene $A B C C 8$ is associated with antidiabetic efficacy of gliclazide in Chinese type 2 diabetic patients," Diabetes Care, vol. 31, no. 10, pp. 1939-1944, 2008.

[153] E. R. Pearson, L. A. Donnelly, C. Kimber et al., "Variation in TCF7L2 influences therapeutic response to sulfonylureas: a GoDARTs study," Diabetes, vol. 56, no. 8, pp. 2178-2182, 2007.

[154] M. G. García-Escalante, V. M. Suárez-Solís, M. T. D. J. LópezÁvila, D. D. C. Pinto-Escalante, and H. Laviada-Molina, "Effect of the Gly972Arg, SNP43 and Pro12Ala polymorphisms of the genes IRS1, CAPN10 and PPARG2 on secondary failure to sulphonylurea and metformin in patients with type 2 diabetes in Yucatán, México," Investigacion Clinica, vol. 50, no. 1, pp. 6576, 2009.

[155] M. L. Becker, A.-J. Aarnoudse, C. Newton-Cheh et al., "Common variation in the NOS1AP gene is associated with reduced glucose-lowering effect and with increased mortality in users of sulfonylurea," Pharmacogenetics and Genomics, vol. 18, no. 7, pp. 591-597, 2008.

[156] A. Seeringer, S. Parmar, A. Fischer et al., "Genetic variants of the insulin receptor substrate-1 are influencing the therapeutic efficacy of oral antidiabetics," Diabetes, Obesity and Metabolism, vol. 12, no. 12, pp. 1106-1112, 2010.

[157] G. Sesti, M. A. Marini, M. Cardellini et al., "The $\operatorname{Arg}^{972}$ variant in insulin receptor substrate-1 is associated with an increased risk of secondary failure to sulfonylurea in patients with type 2 diabetes," Diabetes Care, vol. 27, no. 6, pp. 1394-1398, 2004.

[158] E. R. Pearson, I. Flechtner, P. R. Njølstad et al., "Switching from insulin to oral sulfonylureas in patients with diabetes due to Kir6.2 mutations," The New England Journal of Medicine, vol. 355, no. 5, pp. 467-477, 2006.

[159] Y. Shu, S. A. Sheardown, C. Brown et al., "Effect of genetic variation in the organic cation transporter 1 (OCT1) on metformin action," The Journal of Clinical Investigation, vol. 117, no. 5, pp. 1422-1431, 2007.

[160] M. V. Tzvetkov, S. V. Vormfelde, D. Balen et al., "The effects of genetic polymorphisms in the organic cation transporters OCT1, OCT2, and OCT3 on the renal clearance of metformin," Clinical Pharmacology \& Therapeutics, vol. 86, no. 3, pp. 299306, 2009.

[161] M. L. Becker, L. E. Visser, R. H. N. van Schaik, A. Hofman, A. G. Uitterlinden, and B. H. C. Stricker, "Genetic variation in the organic cation transporter 1 is associated with metformin response in patients with diabetes mellitus," Pharmacogenomics Journal, vol. 9, no. 4, pp. 242-247, 2009.

[162] M. M. H. Christensen, C. Brasch-Andersen, H. Green et al., "The pharmacogenetics of metformin and its impact on plasma metformin steady-state levels and glycosylated hemoglobin A1c," Pharmacogenetics and Genomics, vol. 21, no. 12, pp. 837850, 2011.
[163] I. S. Song, H. J. Shin, E. J. Shim et al., "Genetic variants of the organic cation transporter 2 influence the disposition of metformin," Clinical Pharmacology \& Therapeutics, vol. 84, no. 5, pp. 559-562, 2008.

[164] M. L. Becker, L. E. Visser, R. H. N. van Schaik, A. Hofman, A. G. Uitterlinden, and B. H. C. Stricker, "Genetic variation in the multidrug and toxin extrusion 1 transporter protein influences the glucose-lowering effect of metformin in patients with diabetes: a preliminary study," Diabetes, vol. 58, no. 3, pp. 745-749, 2009.

[165] K. A. Jablonski, J. B. McAteer, P. I. W. de Bakker et al., "Common variants in 40 genes assessed for diabetes incidence and response to metformin and lifestyle intervention in the diabetes prevention program," Diabetes, vol. 59, no. 10, pp. 26722681, 2010.

[166] J. H. Choi, S. W. Yee, A. H. Ramirez et al., "A common 5' UTR variant in MATE2-K is associated with poor response to metformin," Clinical Pharmacology \& Therapeutics, vol. 90, no. 5, pp. 674-684, 2011.

[167] K. Zhou, C. Bellenguez, C. C. A. Spencer et al., "Common variants near ATM are associated with glycemic response to metformin in type 2 diabetes," Nature Genetics, vol. 43, no. 2, pp. 117-120, 2011.

[168] J. Kirchheiner, I. Roots, M. Goldammer, B. Rosenkranz, and J. Brockmöller, "Effect of genetic polymorphisms in cytochrome P450 (CYP) 2C9 and CYP2C8 on the pharmacokinetics of oral antidiabetic drugs: clinical relevance," Clinical Pharmacokinetics, vol. 44, no. 12, pp. 1209-1225, 2005.

[169] Y. Cheng, G. Wang, W. Zhang et al., "Effect of CYP2C9 and SLCO1B1 polymorphisms on the pharmacokinetics and pharmacodynamics of nateglinide in healthy Chinese male volunteers," European Journal of Clinical Pharmacology, vol. 69, no. 3, pp. 407-413, 2013.

[170] W. Zhang, Y.-J. He, C.-T. Han et al., "Effect of SLCO1B1 genetic polymorphism on the pharmacokinetics of nateglinide," British Journal of Clinical Pharmacology, vol. 62, no. 5, pp. 567-572, 2006.

[171] Q. Huang, J.-Y. Yin, X.-P. Dai et al., "Association analysis of SLC30A8 rs13266634 and rs16889462 polymorphisms with type 2 diabetes mellitus and repaglinide response in Chinese patients," European Journal of Clinical Pharmacology, vol. 66, no. 12, pp. 1207-1215, 2010.

[172] Q. Xiang, Y. M. Cui, X. Zhao, L. Yan, and Y. Zhou, "The influence of MDR1G2677T/A genetic polymorphisms on the pharmacokinetics of repaglinide in healthy Chinese volunteers," Pharmacology, vol. 89, no. 1-2, pp. 105-110, 2012.

[173] X.-P. Dai, Q. Huang, J.-Y. Yin et al., "KCNQ1 gene polymorphisms are associated with the therapeutic efficacy of repaglinide in Chinese type 2 diabetic patients," Clinical and Experimental Pharmacology and Physiology, vol. 39, no. 5, pp. 462-468, 2012.

[174] F.-F. Sheng, X.-P. Dai, J. Qu et al., "NAMPT-3186C/T polymorphism affects repaglinide response in Chinese patients with type 2 diabetes mellitus," Clinical and Experimental Pharmacology and Physiology, vol. 38, no. 8, pp. 550-554, 2011.

[175] H. Takane, "Genetic polymorphisms of SLCO1B1 for drug pharmacokinetics and its clinical implications," Yakugaku Zasshi, vol. 131, no. 11, pp. 1589-1594, 2011.

[176] J. He, Z. Qiu, N. Li et al., "Effects of SLCO1B1 polymorphisms on the pharmacokinetics and pharmacodynamics of repaglinide in healthy Chinese volunteers," European Journal of Clinical Pharmacology, vol. 67, no. 7, pp. 701-707, 2011. 
[177] K. Mizushige, T. Tsuji, and T. Noma, "Pioglitazone: cardiovascular effects in prediabetic patients," Cardiovascular Drug Reviews, vol. 20, no. 4, pp. 329-340, 2002.

[178] E. S. Kang, S. Y. Park, H. J. Kim et al., "Effects of Prol2Ala polymorphism of peroxisome proliferator-activated receptor $\gamma 2$ gene on rosiglitazone response in type 2 diabetes," Clinical Pharmacology \& Therapeutics, vol. 78, no. 2, pp. 202-208, 2005.

[179] K.-H. Zhang, Q. Huang, X.-P. Dai et al., "Effects of the peroxisome proliferator activated receptor- $\gamma$ coactivator- $1 \alpha$ (PGC1 $\alpha$ ) Thr394Thr and Gly482Ser polymorphisms on rosiglitazone response in Chinese patients with type 2 diabetes mellitus," The Journal of Clinical Pharmacology, vol. 50, no. 9, pp. 1022-1030, 2010.

[180] H. Makino, I. Shimizu, S. Murao et al., "A pilot study suggests that the G/G genotype of resistin single nucleotide polymorphism at -420 may be an independent predictor of a reduction in fasting plasma glucose and insulin resistance by pioglitazone in type 2 diabetes," Endocrine Journal, vol. 56, no. 9, pp. 10491058, 2009.

[181] H. Sun, Z.-C. Gong, J.-Y. Yin et al., "The association of adiponectin allele $45 T / G$ and $-11377 C / G$ polymorphisms with type 2 diabetes and rosiglitazone response in Chinese patients," British Journal of Clinical Pharmacology, vol. 65, no. 6, pp. 917926, 2008.

[182] H.-L. Liu, Y.-G. Lin, J. Wu et al., "Impact of genetic polymorphisms of leptin and TNF- $\alpha$ on rosiglitazone response in Chinese patients with type 2 diabetes," European Journal of Clinical Pharmacology, vol. 64, no. 7, pp. 663-671, 2008.

[183] J. Kirchheiner, S. Thomas, S. Bauer et al., "Pharmacokinetics and pharmacodynamics of rosiglitazone in relation to CYP2C8 genotype," Clinical Pharmacology \& Therapeutics, vol. 80, no. 6, pp. 657-667, 2006. 

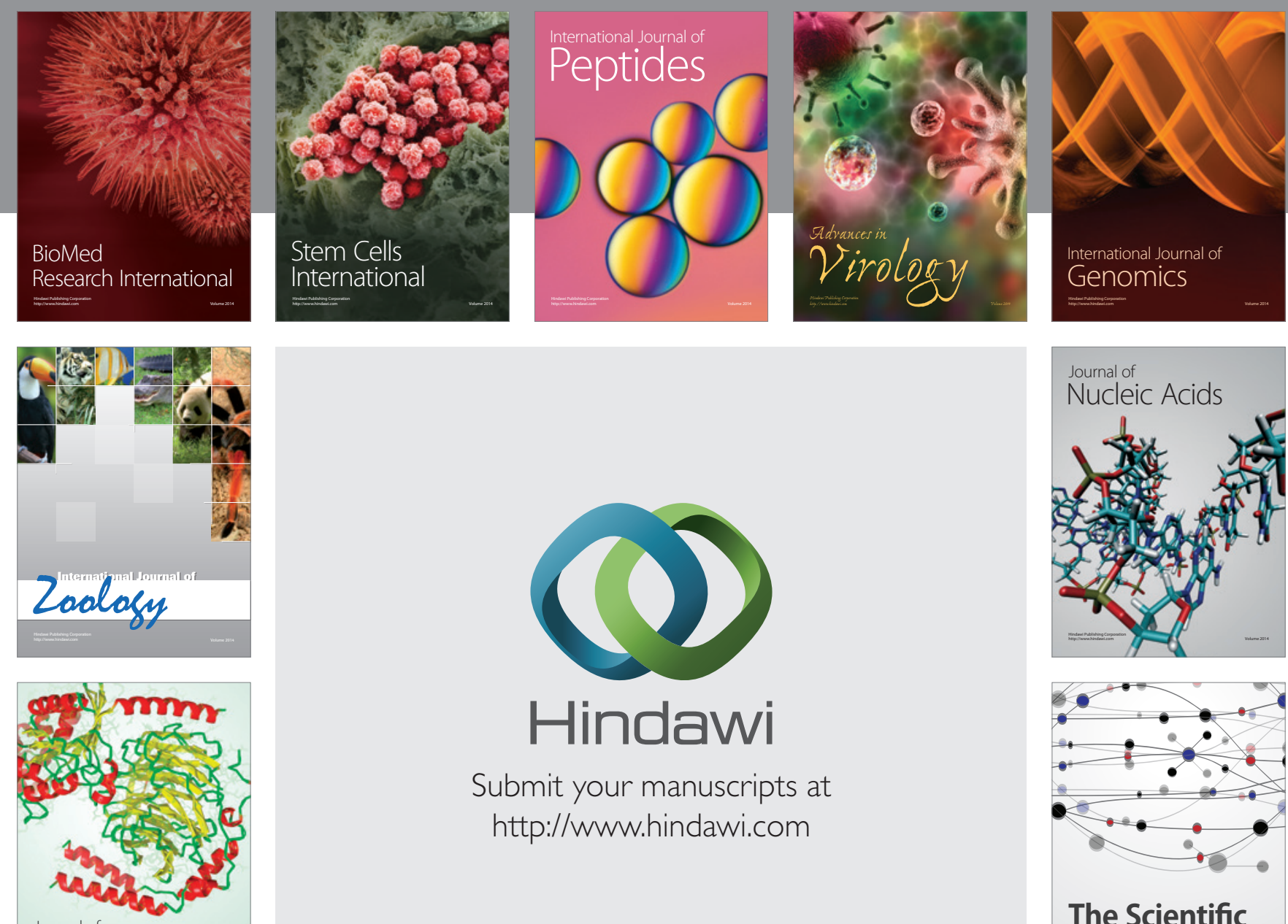

Submit your manuscripts at

http://www.hindawi.com

Journal of
Signal Transduction
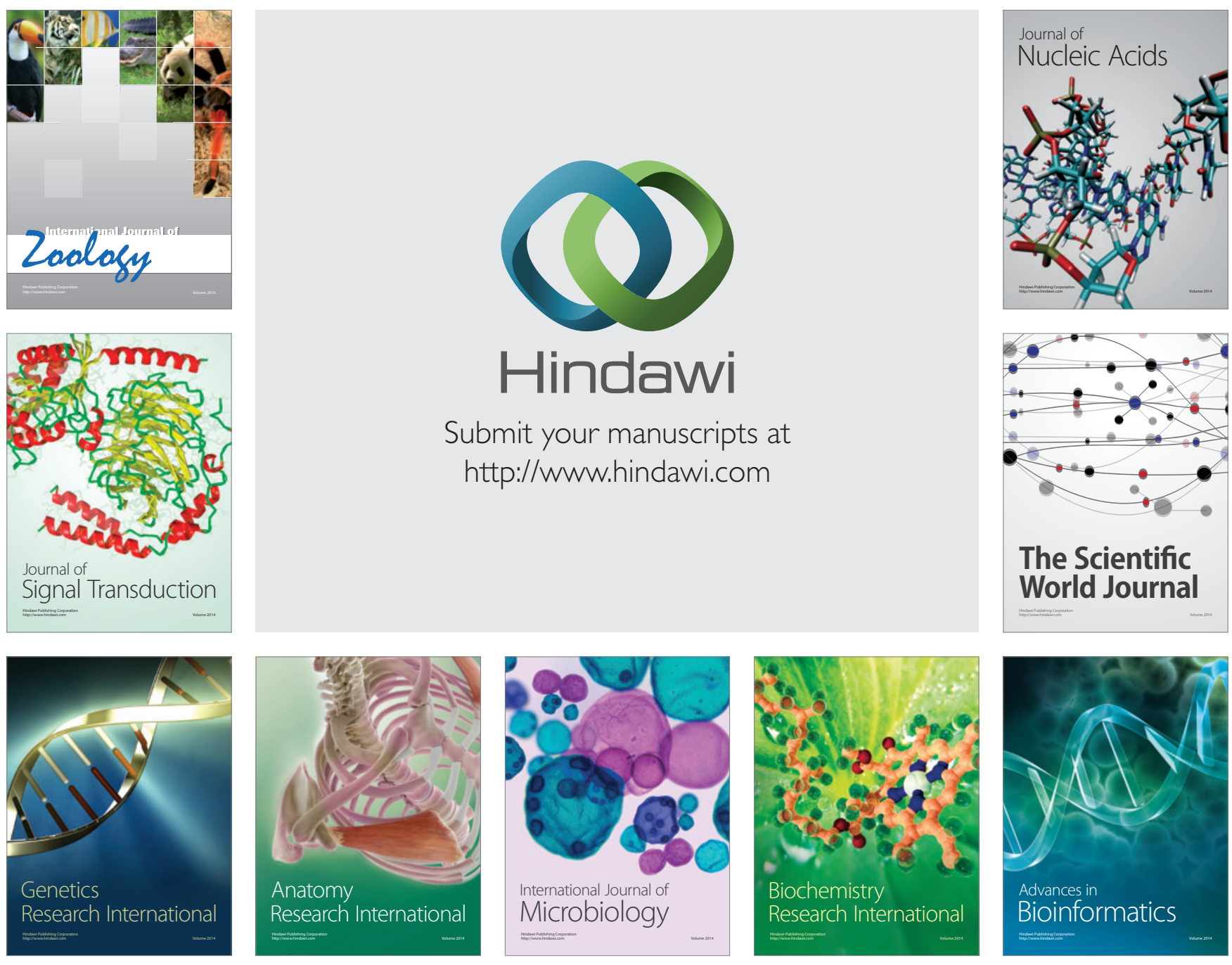

The Scientific World Journal
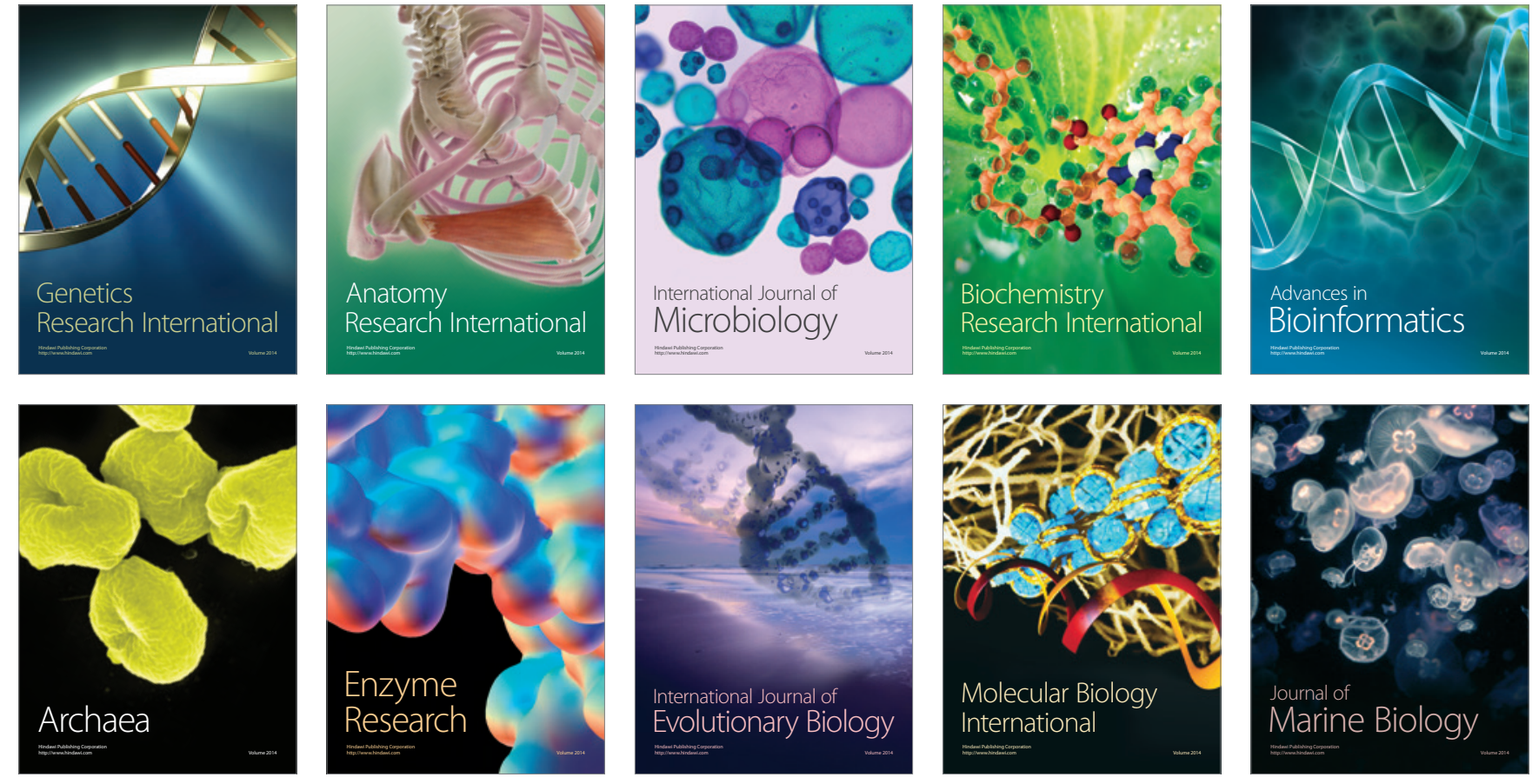